\title{
Hatihun nato: A morphosemantic analysis of Tausug inflection
}

Camlian, Fatmalyn $\bowtie$

Department of Education, Davao de Oro Division, Philippines (fatmalyn.camlian@gmail.com)

De Leon, Maria Guadalupe

University of Mindanao,Tagum, Philippines (guadadeleon_810@yahoo.com)

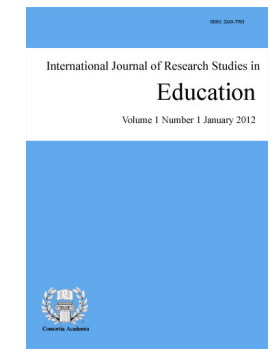

ISSN: 2243-7703 Online ISSN: 2243-7711

Received: 13 January 2022

\section{Abstract}

The study was conducted to identify and create a linguistic recording of the morphosemantic features of Tausug Inflection. Discourse analysis was employed to identify the structure, meaning, and usage of Tausug Inflection. Moreover, this research utilized a phenomenological approach to explore how the Tausug natives preserve their language and their insights on the importance of the language in their cultural identity. This approach was conducted through in-depth interviews and focus group discussions among 14 Tausug participants. Seven of them were for in-depth interviews, and the other seven were for focus group discussion. Findings revealed that there were five Tausug Inflections commonly used by the participants. These inflections were -um, -im, -nag, -mag, and -ma. Moreover, there were five major themes emerged on how the Tausug people preserve their language. These were used at home, used in written and online communication, used during occasions, shared with other cultures, and encouraged proper usage in Masjid. Lastly, there were four major themes revealed on the insights of the Tausug people on the importance of the language in their cultural identity. These were deeply rooted in the culture, sense of cultural pride, language conflict during a conversation, and the importance of research for preservation.

Keywords: teaching English, Tausug, Tausug inflection, morphosemantic features, Philippines 


\section{Hatihun nato: A morphosemantic analysis of Tausug inflection}

\section{Introduction}

As the world races to cope with globalization, indigenous languages are dying almost every two weeks. With the small numbers of native speakers and lack of regard for economically developed societies to their culture, indigenous languages across the globe might vanish forever (Castillo, 2019). For almost 7,000 languages worldwide, 2,700 of these are at risk of extinction. These losses may significantly affect understanding the relationships with one another. Each language around the world gives a unique way of understanding social affairs and human relationships among us. Each death of these languages is a loss for all of us (Old Dominion University, 2020).

Language gives way to understanding one's culture. It is not just a tool for communication. Also, it can be a powerful tool in preserving culture and heritage. Globalization significantly affects the indigenous people in maintaining their mother tongue. Thus, efforts are taken to keep these languages from extinction. In 1999, United Nations introduced International Mother Language Day. This Language Day is celebrated every 21st of February. Also, it is encouraged to use the native language at home and learn the correct pronunciation of words from elders (Goswami, 2019). Language is powerful, and it determines one's identity. Linguists consider it as a cultural, social, and psychological phenomenon. Linguists explore language's uniqueness and how it is acquired and used because of its significance in expression and communication. Thus, language experts scrutinized phonetics and phonology, and semantics and syntax features (Shashkevich, 2019).

On the other hand, the Philippines is a home of 175 languages. However, some of these languages have only a few speakers left, and worst, native tongues are considered extinct because the natives are not using them anymore. Others claimed that the leading cause of this problem is only English, and Filipino are taught and encouraged to use it in school during the colonization of the United States. With this, natives were hesitant to use their language publicly because of discrimination. Some chose not to use their language even at home because it affects their intonation and pronunciation of other languages brought by how they speak their native language (Presse \& Lavalle, 2012). Language binds the unique methods, knowledge, and culture of a particular society. Preserving the language is crucial in protecting the culture. A language without a written record may lose the irreplaceable knowledge of the speakers, such as their ecosystems and geography (Newnum, 2018). Hence, as one of the natives of the Tausug tribe, it is my privileged to scrutinize and explore our language and keep a printed data about it. Thus, this research was undertaken. This study is an initiative to explore our language, specifically looking into the morphosemantic features of Tausug Inflection, show the importance of using our mother tongue, and encourage the natives to be proud of using it whenever and wherever.

Tausug language is the official language of the Tausug ethnic group. This language is used about a million in parts of the Philippines and other neighboring countries such as Malaysia and Indonesia. In the Philippines, the Tausug language is the lingua franca of the Sulu Archipelago, Zamboanga Peninsula, and Southern Palawan. It is part of the Malayo-Polynesian language family and a member of the Visayan branch of Central Philippine languages (Omniglot, 2020). Tan (1967) conducted this study, The Phonology of Tausog: A Descriptive Analysis. This study looked into the phonological system of the Tausug language. He provided a significant description of the phonemes of the Tausug language and presented data that would contribute to redefining the orthography of the Tausug language. Moreover, this study served as a reference to the linguists who looked unto the other components of the Tausug language over the years. However, after 23 years, the Tausug language is still inadequately explored. Hence, I conducted this study to address the inadequacy of exploring and analyzing the Tausug language and provide a reference for the linguists who would like to research more about it. As a native speaker of this language, I studied another component of the Tausug language, which is the morphosemantic features of Tausug Inflection. Also, I provided a comprehensive description of how the natives preserve their 
native tongue. Moreover, this research may be beneficial in teaching the second language to the native speakers of Tausug by providing them the morphological and semantic system of the Tausug Inflection and use it as a reference to provide an activity or a program for second language acquisition. Furthermore, this study was conducted in Barangay Hijo, Maco, Davao de Oro, where the natives moved from Zamboanga and Sulu, which are some of the ancestral territories of the Tausug tribe. This research examined how the natives here preserve their language and culture. It also identified if their language changes and evolves when they only use it inside their homes and community.

\subsection{Purpose of the Study}

The purpose of this study was to analyze the Morphosemantic features of Tausug Inflection. Discourse analysis was employed in this study to identify language characteristics and explore human communication of the natives of the Tausug ethnic group of Barangay Hijo, Maco, Davao de Oro. In addition, this research study generated information through in-depth interviews and focus group discussions and utilized technological devices such as audio recording and cameras to gather precise and credible data from the chosen participants. This study may serve as a reference in understanding the structure, forms, and usage of Tausug Inflection. It aimed to develop information on the system and meaning of words of Tausug Inflection and give a clear understanding of the Tausug tribe. Also, this study aimed to describe the efforts of the natives of the Tausug tribe in preserving their language and identify the insights of the Tausug ethnic group on the importance of the language in their cultural identity. This study may give linguists and other researchers a clear view of the morphosemantic features of the Tausug Inflection and would encourage them to examine this language more and contribute to the effort of preserving the indigenous languages specifically here in Mindanao. On the other hand, this study may be inspired the natives of Tausug to share their language and be encouraged to showcase and preserve their native tongue.

\subsection{Research Questions}

This study sought to describe the morphosemantic analysis of Tausug Inflection and aimed to answer the following questions:

$>$ What are the morphosemantic features of Tausug Inflection?

$>$ How do the Tausug people preserve their language?

$>$ What are the insights of the Tausug ethnic group on the importance of the language in their cultural identity?

\subsection{Theoretical Lens}

This study was seen through the lens of the Sapir-Whorf Hypothesis (1929) as cited by Hussein (2012). This theory was developed by Edward Sapir and Benjamin Lee Whorf and called Linguistic Relativity Principle. The theory states that language influence our thoughts and perceptions. It makes humans perceive the world around us through the language spoken. Different languages have different ways of thinking and attitude toward reality. In this hypothesis, the unique ways of thinking are affected by the native language. Hence, understanding the structures and forms of native languages can be a tool to understand the culture and tradition of the natives. With this, linguists and other language experts can easily understand the ways of Tausug and be encouraged to study more about them and help natives initiate programs and other activities to preserve their language. Moreover, this study scrutinized and described the morphosemantic analysis of Tausug Inflection to look into the ways of life of the Tausug tribe and make a reference in creating learning materials for second language acquisition.

In the Theory of Interlanguage by Larry Salinker (1972) as cited by Al-khresheh (2015), it was described that the transition of the speakers from their first language to second language acquisition could be explored. It is 
observable when the learners use their knowledge in their first language and in learning a new speech. Thus, analyzing the first language will strengthen the bridge of acquiring the second language. As this theory describes, the first language can be the reference in second language acquisition. Thus, this research analyzed the morphosemantics features of Tausug Inflection, which is the native language of the researcher, to come up with a comprehensive reference in acquiring the second language.

\subsection{Significance of the Study}

The findings of this study hoped to benefit the following individuals; first, the Barangay Chieftain of Tausug ethnic group of Barangay Hijo, Maco, Davao de Oro. This research may motivate him to work with Barangay and the municipal officials to create a program preserving and showcasing the language, culture, and traditions of the Tausug tribe. Though there are activities for Muslim people in the area, this kind of event does not fully present nor support the Tausug ethnic group. Moreover, the findings of this research may give him the notion that the tribe's culture and tradition are also acknowledged and worthy of appreciation and acclamation. With this, it may encourage him to participate and suggest activities presenting the Tausug ethnic group.

Secondly, the study may positively affect the natives in our area. Knowing the technical explanation and features of the Tausug language, the natives in Barangay Hijo, Maco, Davao de Oro may work together to preserve the language. The first step in doing this is through giving support to the programs of Barangay Chieftain and actively participate in every program. These initiatives may have a significant impact on the next generation of our tribe. They will be motivated to continue preserving and showcasing the language, culture, and traditions of the Tausug tribe. Also, this study may encourage them to strive for their education and conduct other research about other features of our language.

Lastly, this research hoped to benefit the schools in our area and the neighboring Barangays where the Tausug students are studying. This research may serve as their reference in understanding the language of the Tausug tribe and their culture and traditions. With this, they may create learning materials suited for these students and conduct activities exhibiting the language, culture, and practices of the Tausug tribe and other Indigenous groups. These activities can be another way to preserve our language as these events may give pride to the students and be confident in using our language inside the school. Moreover, for Mother-Tongue Based teachers, the result of this study may provide them with an idea of the structure, forms, and usage of Tausug language, specifically Tausug Inflection, and may consider it to use in their instructions.

\section{Literature review}

\subsection{Understanding the Language and Culture of Tausug Tribe}

Tausug or Tausog is among the most prominent Muslim ethnic group in the Philippines. They are one of the significant migrants from Malaysia, Indonesia, and on the northeastern coast of the island of Borneo. In the Philippines, Tausug inhabits the Sulu Archipelago and southwest of the Mindanao, mainly in Jolo Island. Today, Tausug in the Philippines is roughly 900,000 in numbered (The Editors of Encyclopaedia Britannica, 2021). The Tausug language contains riddles or tigum-tigum. Riddles serve as entertainment for them and often perform during weddings and wakes and during Ramadan. For the Tausug society, a riddle is a fight of wit and wisdom. Also, it serves as an avenue to teach the young generation the value of thinking and be conscious of the nature and objects surrounding them (Tausog Familiarization Course, 2020).

Tausug Literature is said to be rich and flourish from generation to generation. Their literary stories are taught through oral tradition. They call their tales katakata that are mainly about the lives of their Sultan. However, Tausug tales may vary depending on the geographical locations of the Tausug people. One of their stories is Posong or Pusong. It is a story about a man and his adventure in tricking the Sultan and gets away with it. Also, Tausug calls their legend usulan. These legends are primarily about their known lakes, mountains, or

62 Consortia Academia Publishing (A partner of Network of Professional Researchers and Educators) 
their provinces. Kawwn of Bud Tumatangis or The Weeping River is their famous legend. This legend is about Mount Tumatangis, the highest mountain in Sulu, which believed that whenever sailors see its peak, they will lose their sight (Calderon, 2020). Furthermore, the language of Tausug is anchored to the teaching of Islam. Islam is a way of life that goes strongly with the observance of adat, the customary laws, for the Muslim speakers of this language. Hence, profanity among speakers of Bahasa Sug is sanctioned by the Islamic faith and declared haram, or religiously forbidden (Jubilado, Ingilan \& Dumanig, 2015).

On the other hand, Tausug ethnic tribe is the first tribe in the Philippines that was converted to Islam. They follow the Sunni Islamic beliefs and practices, which is the largest branch of the Islam religion. Tausug people believe in the spiritual being those lives in nature, such as in trees and rocks. Some of these spiritual beliefs are their evil spirit named Saytan and Jin, an unseen magical creature. In terms of their folk stories, it is mainly about the adventure of their great ancestors and legends. One of these is the Kaawn of Bud Tumantangis or The Weeping Mountain, which Bud means mountain, and Tumantangis came from the root word tangis, which means to cry. Generally, the beliefs of the Tausug ethnic group are present in their rituals and dances that mostly show their relationship with nature (De Jong, 2010).

Tausug or the people of the sea current depend on the abundance of nature to survive every day. Their primary source of income is through fishing and agriculture. In fishery, they utilize different tools such as nets, hook and line, various types of bamboo traps. In agriculture, coconuts, coffee, and fruit are their primary crops, and they usually raise cattle, chickens, and ducks (Joshua Project, 2020). The Tausug ethnic group values the importance of allegiance; to signify their loyalty, they practice the ritual of blood compact. It shows a depth of bond and commitment. In terms of marriage, they practice the ancient tradition of marriage. The parents arrange the wedding of their children. The groom's parents will give a dowry to the bride's family to signify the start of the couple's union. The dowry can be in different forms, such as money, jewelry, land, crops, or animals (Living In The Philippines, 2020).

In addition, Tausug culture and traditions came from pre-Islamic and are practiced until today. Religion plays an essential role in maintaining the hierarchical structure of the state of Tausug identity. They value the presence of their Imam; as a vital community figure that leads rites, religious counsel, and prayer. The head of their Islamic polity is called Sultan. The political structure of Tausug is regarded as a religious one. It is led by a Sultan consisting of state to the community level of kadi, ulama, and juridical and spiritual advisors. Moreover, mosque officials are consisting of an imam, hatib, and bilal (Countries and their Cultures, 2020).

\subsection{Understanding Morphology and Morphological Analysis of Language}

Morphology is the structure and construction of words. It is one of the linguistic skills that require an understanding of how words are formed. It includes knowing the components of words, such as the root words and suffixes. (Children's Speech \& Language Services, 2020). In understanding morphology, morpheme should first be learned. It is the smallest unit of words with meanings. These meanings depend on how the language transmits the message. You can create a morpheme to form a word and produce content when letters are put together (Janovsky, 2020). Teaching morphology can enhance vocabulary development and reading comprehension. Morphology allows children to manipulate words and construct meaning, and it widens their vocabulary. Understanding the construction of terms helps the students understand more the text they are reading. Direct teaching of morphology can be a great strategy to develop students' reading comprehension and their ability to decode words effectively, spelling, and vocabulary study (Stowe, 2020).

More so, morphology is said to be an important organizing principle of English and other alphabetic languages. However, theories of reading acquisition are disregarded. An article was conducted to develop the view that learning to appreciate morphological relationships may be a vital part of acquiring understanding between printed words and their meanings, represented in the ventral brain pathway of the reading network. It shows that morphology provides an essential degree of regularity across this mapping in English. It suggests that 
this regularity is directly associated with irregularity in the mapping between spelling and sound. Moreover, it shows that while children in primary school display explicit knowledge of morphological relationships, less evidence shows the rapid morphological analysis of printed words that skilled readers exhibit. The results suggested that the acquisition of long-term morphological understanding may be associated with the ongoing development of reading expertise (Rastle, 2018).

In research on Morphology in Language Acquisition, children produce an organized morphological modulation of words during the first year they begin to talk. As they develop their ability in speaking, they improve their expressions of meaning and become oriented with grammatical morphemes such as prefixes, suffixes, prepositions, postpositions, and clitics. However, this process may take several years for the child to master, and Clark presented three reasons. First, the distinctions of meanings might be difficult for the child to learn because of their complexity. Second, examples might be typical for other children but, for some, find it difficult. Lastly, the organization of language might affect the process of morphological acquisition of the child. Like learning suffixes are understood first before prefixes (Clark, 2017).

Furthermore, words were examined to provide a general overview of words through his publication Morphology and implications for English language teaching. Morphology awareness in English enables language teachers to help their learners understand how words enter a language, what they consist of, and how they are formed by combining prefixes, suffixes, and roots. A variety of morphological issues were introduced, such as the concept of morpheme, its types, the distinction between inflections and derivations, exceptions in English morphology and morphs, allomorphs, and the pronunciation of morphemes. Word formation was through derivation, which is by far the most common word-formation process in creating new English words and other word-formation processes such as coinage, compounding, backformation, borrowing, and conversion. Each of these and other methods are examined and exemplified for students of English to develop their awareness. Moreover, some morphological implications for English language teaching, and in discussing these implications for language teaching, particular attention is paid to recent research findings that focus on the explicit teaching of morphological awareness as metalinguistic ability $(\mathrm{Oz}, 2014)$.

Similarly, a study about the effects of morphological awareness on second language vocabulary knowledge: analyzed the impact of morphological treatment in the English morphological awareness tasks. There were fifty-two preparatory class students as participants in his study. Two groups were divided into the experimental and the control group. The experimental group was conducted three hours of morphological guideline and morpheme teaching treatment for twelve weeks, whereas the control group was exposed to traditional vocabulary teaching. The students completed Nation's Vocabulary Size Test, language history questionnaire, and Morphological Awareness Test (Part A and B) to know the effects of morphological treatment on English vocabulary acknowledgment. In the study's findings, the experimental group had shown a higher score on vocabulary recognition than the control group after thirty-six hours of treatment. These results indicate that the participants who obtained morphological treatment considered the morphemes and vocabulary items better than the others who took traditional vocabulary teaching procedures (Akbulut, 2017).

On the other hand, Utah State University conducted a study about the influence of Morphological Awareness on the literacy development of first-grade children. It investigated whether these first-grade children had morphological awareness when they spelled words whether these abilities could predict their performance on word-level reading and spelling measures. The study found out that first graders had morphological awareness and influenced their literacy development (Wolter, D'zatko \& Wood, 2009). Further, literature was reviewed to identify vocabulary outcomes of the students on instruction in morphological analysis strategies with English Language Learners (ELLs) at the University of Minnesota. This article examined the nature of teaching and quality of products for ELLs and those with or at risk of reading disabilities. Nine students met the inclusion criteria for this review. Results suggested that morphological analysis strategies were a promising approach to improving the vocabulary knowledge of ELLs, including those with or at risk of reading disabilities (Brandes \& McMaster, 2017). 
Morphological analysis is an approach that provides grammatical information about words considering their morpheme. This approach is a vital part of natural language processing and can be done in speech synthesis, information extraction, and machine translation. In some morphological analyses, programs to analyze the morphology of words are used. These programs describe the lexical form of words in a text, such as a noun word. Also, this program will identify its gender, number, and case information, and will determine its tense, aspect, and modularity (Literature Review, 2020).

\subsection{Understanding Semantics and Semantic Analysis of Language}

Semantics is the study of the meaning system of a language, and its approaches vary widely. Some viewed that meaning as the relationship between language and the external world (referential or denotative meaning), between a word and the concept it stands for. Other experts said that semantics involves the mental state of the speaker, as reflected in a range of personal, emotive overtones (affective or connotative meaning). A paper to analyze the language features of English advertisements at a semantic level was conducted. The writer has built a corpus of over 20 English advertisements. The semantic features of the language of advertising are summarized and given possible conclusions through the detailed survey of all the advertisements. After a brief introduction to semantics and advertising language, the paper is focused on the linguistic realizations in English advertising from the semantic perspective. The use of the connotative meaning of words, adjectives, coined words, misspelled words, repetition, metaphoric use of words, punning, non-existing words, and the use of ambiguous statements to reveal fuzzy nature were discussed. Advertisers used these words to achieve their persuasive ends (African Research Review, 2011).

Further, a study that highlighted the critical part of questions in understanding the linguistics structure of semantics was conducted that asked three questions on how to scrutinize it, first how language gives basic concepts and ideas of words and idioms. Second, how we identify the parts of sentences are combined to understand their meaning. Lastly, how we know the importance of words and sentences in a particular situation also depends on the context of the speakers (Ladusaw, 2020).

On the other hand, semantic language skills are understanding the correct usage of the meaning of words, phrases, sentences, and paragraphs. Semantic language skills are the ability to identify labels and recognize their categorization, knowledge, and know-how to use adjectives, grasp the functions and state of words, and determine their definition and meaning. Moreover, semantic language skills focus on the knowledge of vocabulary concepts of the children, such as understanding synonyms and antonyms. At a higher level, semantic language skills include knowledge of the complexities of words, such as in figurative languages. Indeed, semantic language skills are fundamental in understanding the world around us and expressing ourselves freely and comprehensibly (Children's Speech and Language Services, 2020).

Furthermore, to expand the English vocabulary for Iraqi Second Language learners, Langacker's Cognitive Linguistic Theory of Domains (1987) was adopted to provide a new sight into vocabulary learning and to expand the vocabulary of Iraqi students. An experimental study on forty-six college students of second-year level from, University of Baghdad, Iraq was conducted. The data of the pre-test and post-test were analyzed using the Statistical Package for Social Sciences editor. The study's findings showed that the progress of more than $(0.05 \leq)$ as far as students' understanding of the semantic domains of the linguistic concepts had been detected. Second, the primary source of difficulty regarding vocabulary acquisition throughout Langacker's theory has been treated. Lastly, the domains theory has proven its effectiveness in accurately comprehending the semantic domains of the English lexical concepts (Aajami, 2019).

Semantic analysis of language describes human communication based on meanings and context, including identifying the text element and categorizing them logically and grammatically. Semantic analysis analyzes the context and structure of text to comprehensibly identify the complex meaning of words (Expert System Team, 2020). The purpose of semantic analysis is to generate the correct meaning of the text. It is the process of 
scrutinizing the meaning of individual words or lexical semantics and the combined individual words. In semantic analysis, elements will be examined, such as hyponymy, homonymy, and polysemy of words. Generally, the semantic analysis draws the meaning representation of a sentence. In doing this, the building blocks of the semantic system should be understood. It includes entities, concepts, relations, and predicates. Entities represent the individualization of words such as a particular person or location. Concepts represent a general category of individuals, such as a person or city. Relations represent between entities and concepts; for example, Tina is a person. Lastly, predicates represent verb structure such as semantic roles and case grammar (Tutorial Point, 2020).

Similarly, semantic analysis is constructing meaning representations. It includes lexical semantics and compositional semantics. Lexical semantics identify the meaning of words, while compositional semantics is concerned with how words are combined to form broader definitions. Overall, semantic analysis means understanding language. It knows the importance of expressions or speech and how to use them (Klapuri, 2007). In natural language processing, semantic analysis is a tool to identify and understand the meaning of text or language. In doing this, different techniques are used. These techniques are the co-reference solution, semantic role labeling, word sense disambiguation, and named entity recognition. In the co-reference resolution, finding all the references to an entity within a text document are done. Semantic role labeling identifies the predicate in a sentence and the method of grammatical classes to determine how the predicate is identified. On the other hand, word sense disambiguation involves identifying the meaning of ambiguous or complex words based on their context. Lastly, named entity recognition identifies the entity of words such as persons, locations, or organizations. It recognizes the complexity of words like the word Seattle. This word can represent a person or location. Named entity recognition can be applied in text classification, topic modeling, content recommendations, trend detection. (Kithulagoda, 2019).

On the other hand, a study was conducted about semantics in Indigenous American Languages particularly, on the languages of the Pacific Northwest. It suggested that in analyzing natural language semantics, specific questions must be considered. First, what semantic properties are common to all languages, and second, how these languages differ in their semantics. This study showed that research on semantic of American languages expanded the empirical knowledge of semantics in non-European languages and provided methodological breakthroughs that impacted linguistic theory (Matthewson, 2017). Generally, semantic analysis is a process of describing, analyzing, and interpreting the meaning of information. In conclusion, semantic analysis of semantic data formed the basis of the cognitive information system. This system of interpretation, description, analysis, and reasoning is conducted (Scott, 2009).

\subsection{Researches about Inflection of Language}

A qualitative study was conducted about the Inflection of Sasak Language in Kuripan Village. This study aimed to analyze the types and the functions of inflection of Meno-Mene dialect, which is the dialect used by the Kuripan villagers in their conversation. This study utilized descriptive and qualitative methods. The study found out 34 inflection morphemes in the Meno-Mene dialect. These morphemes were classified into nouns, verbs, and adjectives. Moreover, several affixes in the Meno-Mene dialect of Kuripan that influences their utterances or expressions were identified in this study (Syarifaturrahman, Hanafi \& Nuriadi, 2017). Inflectional Morphology in the Oromo language was scrutinized to identify its patterns of morphemes and rules for inflections. Description of inflectional forms to determine the inflectional characteristics of the Oromo Language was examined, specifically nouns and verbs. This research provided a comprehensive report of the structures and functions of the inflectional morphology of the Oromo language (Wakweya, 2017).

Further, a study entitled Inflectional morphology in bilingual language processing: An age-of-acquisition study examined the effects of age-of-acquisition (AoA) on grammatical processing, specifically the inflectional morphology in bilinguals. One hundred individuals participated from the Russian and German communities in Berlin. Based on the result of this study using the cross-modal lexical priming technique in which it investigated

66 Consortia Academia Publishing (A partner of Network of Professional Researchers and Educators) 
the stem allomorphs of German verbs, for early AoA showed efficiency in identifying morphosyntactic features and lower efficiency for increasing AoA (Bosch, Veríssimo \& Clahsen, 2019). On the other hand, a study, The Problem of Verbal Inflection in Second Language Acquisition, investigated memory, learning, and grammar as phenomena in the difficulties in teaching a second language. Memory and learning were associated with these difficulties in agreement and past tense marking contributed to the problem in learning verbal inflection. This research suggested that subject-verb agreement is complex for second language learners. This notion was created because of the type of memory it belongs to, which is more on procedural memory rather than declarative (O’Grady, 2006).

Moreover, a study was conducted about the loss of case inflection in Bulgarian and Macedonian. One of the characteristics of Slavic Language is Case Inflection, and it was losing since the $11^{\text {th }}$ and 16 th centuries. Thus, this research was conducted to find out its causes and linguistic changes. It used three methodological approaches to examine it. The first approach was the Corpus method that scrutinized the manuscript from Old Church Slavonic and loses the case inflection. The second was comparing the Bulgarian and Macedonian case systems with the Albanian, Balkan Romance, and Greek case systems based on language contacts. Lastly, a cross-linguistic connection of the case systems of Bulgarian and Macedonian and the rest of the Balkan linguistic area to assess the effect of case loss to universal tendencies evident in the languages of the world (Wahlström, 2017).

\subsection{Researches about Morphosemantics Analysis of Language}

Qualitative research was conducted about the morphosemantic analysis of Mansaka affixes in the Municipality of Maragusan, Province of Davao de Oro, Philippines. There were 14 participants in this study, and it was revealed that the Mansaka used their affixes for description and stating commands or requests. Also, Mansaka affixes were added in the present, past, and future form of verb tenses, and they use their affixes to achieve completeness of expression, adherence to their native grammatical or syntactical rule, avoidance of structural ambiguity, and to widen ideas mean in the sentence (Datulio, 2019). Moreover, a study was conducted about the morphological features of Mandaya and Kalagan languages in the Municipality of Sto. Tomas, Province of Davao del Norte, Philippines. This study examined the languages of Mandaya and Kalagan through in-depth interviews and focus group discussions with 20 participants and found that these participants considered Mandaya and Kalagan languages to have similarities and differences. These two native languages have different words used in different situations, such as for kinship, greetings, and getting to know each other, giving descriptions and taste, giving directions, instructions, and asking for information. Also, Mandaya and Kalagan have their own words used for stating commands, requests and in complaining, asking directions, and words used in the market. Generally, Mandaya and Kalagan languages have conflicting meanings and terminologies and differences in accent (Maduay, 2017).

In the language of Homosexuality, a study about the reasons for using gay terminologies in the academic community and analyzed its linguistic features was conducted. In research, Language of Homosexuality: A Morpho-semantic Analysis, described the patterns of formation in gay words through Morphological analysis. These words are clipped with affixation, variety formation, straight words derivation, popular words derivation, gay word affixation, foreign-sounding, and gay word expressions. In semantic analysis, it explained the semantic processes on the meanings of gay words. These are corporal derivation, mutual comprehension, and variety synonymy. Moreover, the following themes emerged during his interview with 28 gay participants from three college institutions in Tagum City. These are Gay Lingo from Friends, Sex Talks, Making Gossips, Sexual Identity, and Sense of Security (Oficiar, 2019).

In the language of Massively Multiplayer Online Role-Playing Games (or MMORPGs), a case study was conducted about the Morpho-semantic processes in the English language used in a Massively Multiplayer Online Role-Playing Game through a qualitative case study. The study found out that players in Warhammer Online have new and unique words and other semantic changes that have taken place (Daniel, 2009). 
On the other hand, a morphosemantic investigation was conducted on term formation processes in English and Spanish. This article examined 200 English and Spanish terms from the olive oil industry to shed light on their linguistic nature. This was achieved using a corpus which makes it possible to retrieve the units and their contexts from specialized texts. It was considered in the investigation the semantic characteristics and connected the terms' formal and meaning aspects besides considering the derivational features of the relevant terminological processes. It allowed the observation of the close relationship between morphology and semantics in terminological spheres, which is directly linked with the role of these units as a tool for specialized communication (Domínguez, 2016).

Further, in Nigeria, a morpho-semantic analysis of verbs as lexical categories was conducted. It surveys an aspect of word categorization in Ẹdo language (lexical category) with a particular focus on the properties of the verb as a member of this class. Illustrations were provided in the study to justify the dichotomy between different types of words in the language (lexical vs. functional) and the place of the verb in the category of words known as lexical. The analysis showed that the verb possesses rich morphological, syntactic, and semantic features that justify its inclusion in the class of lexical class of words (Omoregbe \& Aigbedo, 2015). In Ethiopia, a study was conducted about the morphosemantic analysis on the personal names of Oromo. This research aims to show the norms and values of the Oromo people by finding meaning and patterns in their names. There were 110 samples of 128 names for both male and female that were derived from the names of native speakers of Oromo students in Haramaya University, Department of Oromo Language and Literature. It was highlighted in the study the morphological features, semantic interpretations, and referential meaning of Oromo personal names to analyze. It was found out that Oromo's unique names were derived from parts of speech specifically, nouns, adjectives, pronouns, and verbs. Moreover, suffixes that were attached to the Oromo unique names were indicative of marking morphemes. Generally, Oromo personal names have meaning, and these meanings could be descriptive, associative, or referential (Gerba, 2014).

Similarly, a morphosemantic analysis of the Kamue personal names was conducted in Nigeria. This was undertaken to examine and show the Kamue (Kamuə) norms and values expressed in their naming patterns. One hundred twenty-eight names for both males and females were used for the analysis, and data were derived from native speakers of Nkafa in twelve (12) selected villages. The analysis suggested birth-order terms indicating a child's birth position and sex; circumstantial names, showing the circumstances surrounding a child's birth, and twins' names. Moreover, it was identified that the structural components, such as noun-based compounds, verb-based compounds, preposition-based compounds, conjunction-based compounds, adverb-based compounds, and adjective-based compounds and their sub-categories in Kamuə proper names. Lastly, the meanings of some of the proper names are predictable from their structural components (Jauro, Ngamsa \& Wappa, 2013).

Also, in Nigeria, A Morpho-Semantic Analysis of Lexical Creativity of Political Speech of Nigeria's Independence Anniversary (2015) was examined. This research scrutinized the linguistic creativity of political speech of Nigeria's independence anniversary of 2015 through a morpho-semantic approach. The address was from the 2015 Independence Day speech of President Muhammadu Buhari of Nigeria, and he used a descriptive approach to conduct his study. It was found out in the study that the speaker employed morphological processes such as acronyms, coinages, compounds borrowings as lexical creativity to drive home his points on a memorable day like the Independence Day celebration (Ofoegbu \& Usar, 2018).

On the other hand, A Morpho-Semantic Analysis was examined in Electronic Product Brands at the State University of Surabaya. This analysis described the types of word formation and how they denote meanings in the brands of electronic products, particularly in the United States, the United Kingdom, and Japan. It was found out in this study that there were six types of word-formation processes in the electronic brands such as compounding, blending, clipping, coinage, abbreviation, and acronym. Moreover, it was found out that there were five classifications of frame semantic, namely: fruit as a brand, place as a brand, a person as a brand, product as a brand, and concept as a brand (Viramdani \& Himmawati, 2017). 


\section{Methodology}

Research Design - The study is a qualitative research design employing discourse analysis using morphosemantic analysis as its method. The process of qualitative research begins with philosophical assumptions that the inquirers make in deciding to undertake a qualitative study. Researchers bring their worldviews, paradigms, or sets of ideas to the research project (Creswell, 2013). Thus, in this study, I used my own experiences and beliefs to deal with the participants and allow them to express themselves freely as one of the natives of the Tausug tribe. Qualitative research focuses on understanding human lived experiences. It is used to understand people's beliefs, experiences, attitudes, behavior, and interactions. It listens to the voice of the participants on a particular issue or study and allows them to share their ideas freely and comfortably since it is often less formal. In the qualitative approach, the participants have an active role in the study and voice their beliefs and disagreements about a particular topic. (Pathak, Jena, \& Kalra, 2013).

On the other hand, this study utilized the discourse analysis to identify the structure, meaning, and usage of Tausug Inflection. Williams (2007) identified discourse or content analysis as an exploration of verbal, visual, behavioral patterns, themes, or biases of human communication. Discourse analysis is used to identify specific characteristics from the content in human communications. This analysis is applied through different means of communication, including books, newspapers, and films, as well as other forms to identify patterns, themes, or biases. Furthermore, discourse analysis concentrates on oral language with a focus on face-to-face communication. It investigates features of speech that are small and specific or complex and abstract. It pays attention to how language in context is organized at and above the level of the sentence. One of the crucial functions of discourse analysis in linguistics is the understanding of conventions of language use (Barton, 2002).

Moreover, since this research described the lived experiences of the participants, I utilized the qualitative research design using a phenomenological approach to answer the last two research questions of the study. The phenomenological approach allows the researcher to explore human experiences and perceptions. It aims to produce in-depth knowledge of phenomena and use lived experiences to describe and analyze (Yliopisto, 2010). The purpose of the phenomenological approach is to distinguish specific phenomena from the responses of the participants. Interviews, observations, and discussions realized these responses. A phenomenological approach is concerned with the personal knowledge and experiences of the participants and their viewpoints (Lester, 1999). Hence, in this research, I described the individual views, and experiences of the participants about the preservation of their language and their insights on the importance of the language in their cultural identity.

Research Participants - The research participants of my study were the natives of the Tausug ethnic group of Barangay Hijo, Maco, Davao de Oro. There were 14 natives of the Tausug tribe who were involved in this study. Seven of them were in the focus group discussion and another 7 for the in-depth interview. In a qualitative research study, 5-25 research participants were suggested by Creswell (1998) as cited by Moran (2013). The identified participants of my research were enough to grasp the information needed for this study. In choosing participants in the focus group discussion, I considered homogeneity. These participants have in common such as characteristics, occupation, age, or gender. Sage Publications (2020) recommended five to eight participants in an interview that allow them to express their ideas and expertise. Moreover, in focus group discussion, seven members freely discussed their knowledge and insights of Tausug Language. Focus group discussion aims to obtain several information and perspectives of a particular topic or question. The participants are free to talk about their beliefs, opinions, and ideas (HERD Publication, 2016).

On the other hand, I have selected 7 participants for the in-depth interview. In the in-depth interview, participants gave their individualized knowledge and insights about the Tausug language. Boyce and Neale (2006) stated that an in-depth interview provides more profound and detailed information and offers a complete picture of a topic. It gives more comprehensible individual interviews that explore participants' unique perceptions and ideas. Further, this study had the following inclusion criteria of the participants: the participants were bona fide residents of Barangay Hijo, Maco, Davao de Oro; natives of the Tausug ethnic group; fluent in 
using the Tausug language; natives who have been practicing the culture and tradition of Tausug tribe; Tausug natives who were willing to participate in the study; and those who were present during the time of interview. On the other hand, this study had the following exclusion criteria: natives of Tausug that were not residents of Barangay Hijo, Maco, Davao de Oro; Tausog natives in Barangay Hijo, Maco, Davao de Oro but not fluent in using the Tausug language; Tausug natives who were not oriented and practicing the culture and tradition of Tausug tribe; natives who were not mentally stable of expressing their ideas, experiences, and opinions; Tausug natives who were not willing to participate in the study; and those who were not present during the time of interview. In addition, the participants had the right to withdraw their participation in the study at any time without penalty. They had the utmost accountability in filling up the consent form but may withdraw their consent and wish to discontinue their participation without waving any legal claims.

Data Collection - In this research, I utilized in-depth interviews and focused group discussions to acquire relevant and specific information for this study. In conducting these, I took several steps to ensure the reliability and validity of the information collected. Before conducting this study, I had several consultations with my adviser on concepts and processes I should know and consider in gathering data. After these, I wrote a letter of consent to the Barangay Chieftain of Tausug Community, Alonto S. Aradiani, in Barangay Hijo, Maco, Davao De Oro, to formally ask permission to conduct this study and involved some of the natives as participants in the area. When Chieftain Ardiani gave the consent to conduct the study, I discussed with my chosen gatekeeper to be guided in interviewing the participants. A gatekeeper acts as a middleman between the researcher and the participants to gain access to the community in gathering data, as defined by Durham University (2020). The participants were chosen through a purposeful sample technique with the criteria that these informants have significant knowledge about the language and used this as their primary mode of communication. I asked approval from them and informed them of their rights as informants of this study. I also discussed with them the importance of the research to our language and the community for them not to be hesitant in giving their responses.

In conducting the in-depth interview and group discussion, I used several devices for accuracy and easy access to the data gathered. It included an audio recorder and a camera. The voice recorder gave an exact word of the participants' responses. It gave a clear voice to the informants and made the data easy to transcribe, translate, and analyze. On the other hand, the camera gave additional information that was not taken by the voice recorder. These were the facial expressions and gestures of the participants while giving their responses. It provided essential knowledge on how the participants expressed their ideas and opinions using their language. Moreover, in this pandemic, I implemented specific safety measures in gathering the data to avoid the transmission and spread of the COVID-19 virus. Before the interview, I oriented the participants on the importance of adhering to the mandated procedures given by the Inter-Agency Task Force (IATF) in ensuring the safety of everyone. Thus, I prepared alcohol for sanitation, and made sure social distancing was observed during the interview. Also, I considered wearing face masks and face shields during the conduct of the interview.

Data Analysis - In this research, I utilized thematic analysis to treat the gathered data from in-depth interviews and focused group discussions. I applied thematic analysis to analyze qualitative data and identify interrelated topics, ideas, and patterns of meaning in an organized manner, as stated by Caulfield (2020). On the other hand, I applied morphosemantics analysis to arrange and organize the Tausug words systematically. In the process of morphosemantic analysis, I categorized words into their morphological components and interpreted them semantically, as suggested by Deléger, Namer, and Zweigenbaume (2009). Creswell (2012) presented six steps in analyzing the data. These steps are collecting the data, preparing the data for analysis, reading through the data, coding the data, coding the text for Themes to be used in the study, and coding the text for description to be used in the study.

I utilized these steps in analyzing the gathered data in this study. First, I collected the data through focus group discussion and in-depth interviews using a camera, audio recording, and observation. The data gathered were filed and arranged in a computer file. It was kept and secured for confidentiality and to avoid leaking of

70 Consortia Academia Publishing (A partner of Network of Professional Researchers and Educators) 
information. Second, I organized the data for analysis. The data gathered were transcribed into written statements. I transcribed the data collected intently and correctly through listening to the audio recordings and watching the video of the interviews. Also, I converted notes into organized text, and written down the relevant observations from the camera. Third, read all the data. To thoroughly analyze and interpret the data, reading and understanding the transcribed materials was prioritized. In doing this, I read the gathered data multiple times and made an analysis each time. I made descriptions and considered the possible interpretation of the data. Fourth, coding the data. Creswell (2012) defines coding as the process of categorizing and labeling text to draw themes. In this step, after thoroughly analyzing the data, I divided them into groups and labeled them accordingly. Moreover, I organized these groups according to the similarities of ideas and insights given by the participants during the in-depth interviews and group discussions. Fifth, I went back to the coded data and identified interrelated information from it. I organized the relevant information that would answer my research questions and provided descriptions of the similar coded data with the helped of my data analyst. Lastly, I went back to the coded data and examined them. This time I identified the themes generated from my grouped data. I discussed these themes through narrative discussion. Moreover, I showed the research findings through tables and descriptions with the helped again of my data analyst.

\section{Results}

The study participants were the selected 14 natives of the Tausug tribe in Barangay Hijo, Municipality of Maco, Province of Davao de Oro. As presented in Table 1, 14 Tausug natives participated in this study. Seven of them were assigned in a focus group discussion, and the remaining seven were for an in-depth interview.

Table 1

Participants' Information

\begin{tabular}{ccccc}
\hline Pseudonym & Age & Gender & Ethnicity & Study Group \\
\hline $008 \mathrm{BR}$ & 80 & Female & Tausug & IDI \\
058BG & 85 & Female & Tausug & IDI \\
$056 \mathrm{BA}$ & 65 & Female & Tausug & IDI \\
007BD & 70 & Female & Tausug & IDI \\
$095 \mathrm{UI}$ & 59 & Male & Tausug & IDI \\
$085 \mathrm{UA}$ & 58 & Male & Tausug & IDI \\
$074 \mathrm{UE}$ & 47 & Male & Tausug & FGD \\
$072 \mathrm{BM}$ & 27 & Female & Tausug & FGD \\
$042 \mathrm{BL}$ & 24 & Female & Tausug & FGD \\
$084 \mathrm{BH}$ & 48 & Female & Tausug & FGD \\
$012 \mathrm{BB}$ & 21 & Female & Tausug & FGD \\
$013 \mathrm{BR}$ & 31 & Female & Tausug & FGD \\
$042 \mathrm{BW}$ & 24 & Female & Tausug & \\
$084 \mathrm{BN}$ & 48 & Female & &
\end{tabular}

4.1 Research Question No. 1: What are the morphosemantic features of Tausug Inflection?

Research question 1 of this study presents the morphosemantic features of Tausug Inflection. Morphosemantic elements of language show how the words are formed and the meaning of these words. In this study, I identified and analyzed the Tausug Inflections with words that these inflections are used. I categorized these words into tables according to their linguistic processes. Moreover, I presented in tables below the Tausug Inflections according to their functions and the Tausug words inflected with the specific Tausug Inflection and their lexical category. Also, I presented the morphological process of these words to show how the Tausug Inflection changes the base form of Tausug words. Moreover, I have given the meaning of words and their sample sentences to present how Tausug Inflections change the meaning of these words.

Morphosemantic Analysis - In this research, I employed a Morphosemantic analysis to present the morphosemantic features of Tausug Inflection and show how Tausug words change with Tausug Inflection. Literature Review (2020) defined morphological analysis as an approach that provides grammatical information 
about words considering their morpheme. This analysis is a vital part of natural language processing and applies in speech synthesis, information extraction, and machine translation. On the other hand, Expert System Team (2020) identified that semantic language analysis describes human communication based on meanings and context. The Tausug Inflections and words presented in this study are the common words use by the participants every day. Before conducting in-depth interviews and focus group discussions, I asked the participants to list down words they commonly use daily. I also instructed them to list down words they can form using the base form of words they have given. I have given them sample words for them to understand my instructions. Since the participants know their language well, they did not have any difficulties listing down those Tausug words. Below are the Tausug Inflections presented into tables according to their functions. Shown in Table 2 is the Morphosemantic Features of Tausug Inflection as Infinitive Verb (to + verb), Table 3 is the Morphosemantic Features of Tausug Inflection as Past form of the verb, Table 4 is the Morphosemantic Features of Tausug Inflection as Future form of the verb, Table 5 is the Morphosemantic Features of Tausug Inflection as Progressive form of the verb. Lastly, Table 6 is the Morphosemantic Features of Tausug Inflection as Adjective.

Table 2

Morphosemantic Features of Tausug Inflection as Infinitive verb (to + verb)

\begin{tabular}{|c|c|c|c|c|c|c|}
\hline $\begin{array}{c}\text { Tausug } \\
\text { Inflection }\end{array}$ & $\begin{array}{l}\text { Tausug Base } \\
\text { Word }\end{array}$ & $\begin{array}{l}\text { With Inflection } \\
\text { Tausug Word }\end{array}$ & $\begin{array}{c}\text { Lexical } \\
\text { Category }\end{array}$ & $\begin{array}{c}\text { Morphological } \\
\text { Process } \\
\end{array}$ & Meaning & Sample Sentence \\
\hline \multirow{17}{*}{-um Inflection } & Kaon & Kumaon & Verb (V.) & Infixation & To eat & $\begin{array}{l}\text { Mabaya kuno kumaon say'ing } \\
\text { hi ina. }\end{array}$ \\
\hline & $\begin{array}{l}\text { (Eat) } \\
\text { Luto }\end{array}$ & Lumuto & Verb (V.) & Infixation & To cook & $\begin{array}{l}\text { Mother wants to eat a banana. } \\
\text { Bang kaw mabaya lumuto, } \\
\text { hinanga na biyaon. }\end{array}$ \\
\hline & (Cook) & & & & & If you want to cook, do it now. \\
\hline & Hinang & Huminang & Verb (V.) & Infixation & To work & $\begin{array}{l}\text { Huminang kaw biyaon? } \\
\text { Are you going to work today? }\end{array}$ \\
\hline & (Work) & & & & & \\
\hline & $\begin{array}{l}\text { Lasa } \\
\text { (Love) }\end{array}$ & Lumasa & Verb (V.) & Infixation & To love & $\begin{array}{l}\text { Lumasa ra sa 'yan kaw kaniya. } \\
\text { You will eventually learn to } \\
\text { love him. }\end{array}$ \\
\hline & Langoy & Lumangoy & Verb (V.) & Infixation & To swim & $\begin{array}{l}\text { Madto na kita lumangoy } \\
\text { pakalaw-man. }\end{array}$ \\
\hline & (Swim) & & & & & $\begin{array}{l}\text { Let us go to swim to the deeper } \\
\text { part of the sea. }\end{array}$ \\
\hline & Labay & Lumabay & Verb (V.) & Infixation & To pass by & $\begin{array}{l}\text { Lumabay ha marayaw dan. } \\
\text { To pass by in the right path. }\end{array}$ \\
\hline & (Pass by) & & & & & \\
\hline & Dihil & Dumihil & Verb (V.) & Infixation & To give & $\begin{array}{l}\text { Marayaw in dumihil pa } \\
\text { karaya-wan ha lasya mo. }\end{array}$ \\
\hline & (Give) & & & & & $\begin{array}{l}\text { It is good to give for the benefit } \\
\text { of your family. }\end{array}$ \\
\hline & $\begin{array}{l}\text { Lingkat } \\
\text { (Beau- } \\
\text { tiful) }\end{array}$ & Lumingkat & Verb (V.) & Infixation & $\begin{array}{c}\text { To be } \\
\text { beautiful }\end{array}$ & $\begin{array}{l}\text { Lumingkat kaw bang in akkal } \\
\text { mo para-yawon mo. } \\
\text { To be beautiful is to have a } \\
\text { good character. }\end{array}$ \\
\hline & Lagko & Lumagko & Verb (V.) & Infixation & To get bigger & $\begin{array}{l}\text { Lumagko kaw bang kaw } \\
\text { kumaon sayol. }\end{array}$ \\
\hline & (Big) & & & & & $\begin{array}{l}\text { To get bigger, you must eat } \\
\text { vege-tables. }\end{array}$ \\
\hline & Katawa & Kumatawa & Verb (V.) & Infixation & To laugh & $\begin{array}{l}\text { Ayaw kalupahi in kumatawa } \\
\text { bisan ha lawum kasusa-han. }\end{array}$ \\
\hline & (Laugh) & & & & & $\begin{array}{l}\text { Do not forget to laugh even at } \\
\text { the worst times. }\end{array}$ \\
\hline
\end{tabular}

The first Tausug Inflection is the -um Inflection. This Tausug Inflection is an inflectional affix, an infix to be specific, that when inflected in Tausug words will function as an infinitive verb, the to $+v e r b$. The common Tausug words with -um inflections are the following: kumaon, from the base word kaon with an English transition, eat, kaon inflected with-um is kumaon and now has an English transition to eat; the word lumuto from the base word luto with English transition cook inflected with -um will become lumuto and now has an English transition to cook; the word huminang, from the base word hinang with an English transition work, hinang inflected with -um is huminang and now has an English transition to work; the word lumasa, from the base word lasa with an English transition love, lasa inflected with -um is lumasa and now has an English transition to love; 
and the word lumangoy, from the base word langoy with an English transition swim, langoy inflected with -um is lumangoy and now has an English transition to swim.

Also, the word lumabay, from the base word labay with an English transition pass by, labay inflected with -um is lumabay and now has an English transition to pass by. The word dumihil from the base word dihil with an English transition give, dihil inflected with -um is dumihil and has now an English transition to give. The word lumingkat from the base word lingkat with an English transition beautiful, lingkat inflected with -um is lumingkat and now has an English transition to love. The word lumagko from the base word lagko with an English transition big, lagko inflected with -um is lumagko and now has an English transition to get bigger. Lastly, the word kumatawa from the base word katawa with an English transition laugh, katawa inflected with -um is kumatawa and now has an English transition to laugh.

Table 3

Morphosemantic Features of Tausug Inflection as Past form of the verb

\begin{tabular}{|c|c|c|c|c|c|c|}
\hline $\begin{array}{l}\text { Tausug } \\
\text { Inflection }\end{array}$ & $\begin{array}{l}\text { Tausug Base } \\
\text { Word }\end{array}$ & $\begin{array}{l}\text { With Inflection } \\
\text { Tausug Word }\end{array}$ & $\begin{array}{l}\text { Lexical } \\
\text { Category }\end{array}$ & $\begin{array}{l}\text { Morphological } \\
\text { Process }\end{array}$ & Meaning & Sample Sentence \\
\hline \multirow{19}{*}{-im Inflection } & Kaon & Kimaon & Verb (V.) & Infixation & Ate & \\
\hline & & & & & & Kimaon hi ina say'ing. \\
\hline & (Eat) & & & & & Mother ate the banana. \\
\hline & Luto & Limuto & Verb (V.) & Infixation & Cooked & $\begin{array}{l}\text { Limuto ako say'ing para } \\
\text { kaunon ganagana. }\end{array}$ \\
\hline & (Cook) & & & & & I cooked banana for later. \\
\hline & Hinang & Himinang & Verb (V.) & Infixation & Worked & $\begin{array}{l}\text { Himinang hi ama mo kahapon. } \\
\text { Your father worked yesterday. }\end{array}$ \\
\hline & (Work) & & & & & \\
\hline & Lasa & Limasa & Verb (V.) & Infixation & Loved & $\begin{array}{l}\text { Limasa kuno siya kaymo. } \\
\text { He loved you. }\end{array}$ \\
\hline & (Love) & & & & & \\
\hline & Langoy & Limangoy & Verb (V.) & Infixation & Swam & $\begin{array}{l}\text { Limangoy sila pa- kalawman } \\
\text { They swam deeply in the sea. }\end{array}$ \\
\hline & $\begin{array}{l}\text { (Swim) } \\
\text { Labay }\end{array}$ & Limabay & Verb (V.) & Infixation & Passed by & $\begin{array}{l}\text { Limabay na sila kaynaa. } \\
\text { They already passed by earlier. }\end{array}$ \\
\hline & (Pass by) & & & & & \\
\hline & $\begin{array}{l}\text { Dihil } \\
\text { (Give) }\end{array}$ & Dimihil & Verb (V.) & Infixation & Gave & $\begin{array}{l}\text { Dimihil sila badjo ha mga bata. } \\
\text { They gave clothes to the } \\
\text { children. }\end{array}$ \\
\hline & Lingkat & Limingkat & Verb (V.) & Infixation & Got beautiful & $\begin{array}{l}\text { Limingkat pa kuno in anak niya } \\
\text { budjang. }\end{array}$ \\
\hline & $\begin{array}{l}\text { (Beau- } \\
\text { tiful) }\end{array}$ & & & & & $\begin{array}{l}\text { Her daughter got more } \\
\text { beautiful. }\end{array}$ \\
\hline & Lagko & Limagko & Verb (V.) & Infixation & $\begin{array}{c}\text { Got } \\
\text { bigger }\end{array}$ & $\begin{array}{l}\text { Limagko na in mga kuting yan. } \\
\text { Those cats got bigger. }\end{array}$ \\
\hline & (Big) & & & & & \\
\hline & Katawa & Kimatawa & Verb (V.) & Infixation & Laughed & $\begin{array}{l}\text { Kimatawa siya sin bisara ko. } \\
\text { She laughed at my stories. }\end{array}$ \\
\hline & (Laugh) & & & & & \\
\hline
\end{tabular}

The second Tausug Inflection is the -im Inflection. This Tausug Inflection is an inflectional affix, an infix to be specific, that when inflected in Tausug words will function as the past form of the verb. The common Tausug words with -im inflections are the following: the word kimaon, from the base word kaon with an English transition eat, kaon inflected with -im is kimaon and now has an English transition ate; the word limuto from the base word luto with English transition cook inflected with -im will become limuto and now has an English transition cooked; and the word himinang, from the base word hinang with an English transition work, hinang inflected with -im is himinang and now has an English transition worked.

Another word is limasa which from the base word lasa with an English transition love, lasa inflected with -im is limasa and now has an English transition loved. The word limangoy, from the base word langoy with an English transition swim, langoy inflected with -im is limangoy and now has an English transition swam. The word limabay, from the base word labay with an English transition pass by, labay inflected with -im is limabay and now has an English transition passed by. The word dimihil from the base word dihil with an English transition give, dihil inflected with -im is dimihil and now has an English transition gave. The word limingkat 
from the base word lingkat with an English transition beautiful, lingkat inflected with -im is limingkat and now has an English transition got beautiful. The word limagko from the base word lagko with an English transition big, lagko inflected with -im is limagko and now has an English transition got bigger. Lastly, the word kimatawa from the base word katawa with an English transition laugh, katawa inflected with -im is kimatawa and now has an English transition laughed.

\section{Table 4}

Morphosemantic Features of Tausug Inflection as Future form of the verb

\begin{tabular}{|c|c|c|c|c|c|c|}
\hline $\begin{array}{l}\text { Tausug } \\
\text { Inflection }\end{array}$ & $\begin{array}{l}\text { Tausug Base } \\
\text { Word }\end{array}$ & $\begin{array}{l}\text { With Inflection } \\
\text { Tausug Word }\end{array}$ & $\begin{array}{c}\text { Lexical } \\
\text { Category }\end{array}$ & $\begin{array}{l}\text { Morphological } \\
\text { Process }\end{array}$ & Meaning & Sample Sentence \\
\hline \multirow{15}{*}{$\begin{array}{l}\text {-mag } \\
\text { Inflection }\end{array}$} & $\begin{array}{l}\text { Kaon } \\
\text { (Eat) }\end{array}$ & Magkaon & Verb (V.) & Prefixation & Will eat & $\begin{array}{l}\text { Magkaon ra baha in mga bata } \\
\text { "yan sayol? } \\
\text { Do you think those children } \\
\text { will eat vege-tables? }\end{array}$ \\
\hline & Luto & Magluto & Verb (V.) & Prefixation & Will cook & $\begin{array}{l}\text { Magluto ako sayol ganagana. } \\
\text { I will cook vegetables later. }\end{array}$ \\
\hline & $\begin{array}{l}(\text { Cook) } \\
\text { Hinang }\end{array}$ & Mag-hinang & Verb (V.) & Prefixation & Will work & $\begin{array}{l}\text { Maghi-nang kuno hi ama } \\
\text { kunsom. }\end{array}$ \\
\hline & (Work) & & & & & $\begin{array}{l}\text { Your father will work } \\
\text { tomorrow. }\end{array}$ \\
\hline & Lasa & Maglasa & Verb (V.) & Prefixation & Will love & $\begin{array}{l}\text { Maglasa kita niyo ampa nato } \\
\text { kabakan in kasan-yangan. }\end{array}$ \\
\hline & (Love) & & & & & $\begin{array}{l}\text { We will love one another for us } \\
\text { to find peace. }\end{array}$ \\
\hline & Langoy & Maglangoy & Verb (V.) & Prefixation & Will swim & $\begin{array}{l}\text { Magla-ngoy na kuno in mga } \\
\text { bata yadto. }\end{array}$ \\
\hline & $\begin{array}{l}\text { (Swim) } \\
\text { Labay }\end{array}$ & Maglabay & Verb (V.) & Prefixation & Will pass by & $\begin{array}{l}\text { The children will swim now. } \\
\text { Maglabay na adja in tahun sa } \\
\text { way pakaw nahinang. }\end{array}$ \\
\hline & (Pass by) & & & & & $\begin{array}{l}\text { Your years will pass by without } \\
\text { accom-plishment. }\end{array}$ \\
\hline & Dihil & Magdihil & Verb (V.) & Prefixation & Will give & $\begin{array}{l}\text { Magdihil kuno sila badjo ha } \\
\text { mga bata. }\end{array}$ \\
\hline & (Give) & & & & & $\begin{array}{l}\text { They will give clothes to the } \\
\text { children. }\end{array}$ \\
\hline & $\begin{array}{l}\text { Lingkat } \\
\text { (Beau- } \\
\text { tiful) }\end{array}$ & *Magli-lingkat & Verb (V.) & $\begin{array}{l}\text { Prefixation } \\
\text { and } \\
\text { Reduplication }\end{array}$ & $\begin{array}{l}\text { Will be } \\
\text { beautiful }\end{array}$ & $\begin{array}{l}\text { Magliling-kat pa san in mga } \\
\text { budjang yan. } \\
\text { These ladies will be beautiful } \\
\text { as years go by. }\end{array}$ \\
\hline & $\begin{array}{l}\text { Lagko } \\
\text { (Big) }\end{array}$ & *Magla-lagko & Verb (V.) & $\begin{array}{l}\text { Prefixation } \\
\text { and } \\
\text { Reduplication }\end{array}$ & $\begin{array}{l}\text { Will get } \\
\text { bigger }\end{array}$ & $\begin{array}{l}\text { Magla-lagko pa san in mga bata } \\
\text { yan. } \\
\text { These children will still get } \\
\text { bigger. }\end{array}$ \\
\hline & Katawa & Mag-katawa & Verb (V.) & Prefixation & Will laugh & $\begin{array}{l}\text { Magka-tawa maray ako } \\
\text { maka-dungog ha bisara mo. }\end{array}$ \\
\hline & (Laugh) & & & & & $\begin{array}{l}\text { I will probably laugh with } \\
\text { your stories. }\end{array}$ \\
\hline
\end{tabular}

The third Tausug Inflection is the -mag Inflection. This Tausug Inflection is an inflectional affix, a prefix to be specific, that when inflected in Tausug words will function as a future form of the verb using the modal verb, will. The common Tausug words with -mag inflections are the following: the word magkaon, from the base word kaon with an English transition eat, kaon inflected with -mag is magkaon and now has an English transition will eat; the word magluto from the base word luto with English transition cook and when inflected with -mag will become magluto and now has an English transition will cook; the word maghinang from the base word hinang with an English transition work, hinang inflected with -mag is maghinang and now has an English transition will work; and the word maglasa, from the base word lasa with an English transition love, lasa inflected with -mag is maglasa and now has an English transition will love.

The Tausug word maglangoy, from the base word langoy with an English transition swim, langoy inflected with -mag is maglangoy and has now an English transition will swim. Another word is maglabay, from the base word labay with an English transition pass by, labay inflected with -mag is maglabay and now has English 
transition will pass by. The word magdihil from the base word dihil with an English transition give, dihil inflected with -mag is magdihil and now has an English transition will give. The word maglilingkat from the base word lingkat with an English transition beautiful, lingkat inflected with -mag is maglingkat, but the initial consonant of the stem lingkat should be reduplicated to make the word correct and appropriate to use as the future form of the verb. Thus, maglingkat should be maglilingkat which has now an English transition will be beautiful. Also, the word maglalagko from the base word lagko with an English transition big, lagko inflected with -mag is maglagko, but the initial consonant of the stem lagko should be reduplicated to make the word correct and appropriate to use as the future form of the verb. Thus, maglagko should be maglalagko which has now an English transition will get bigger. Lastly, magkatawa from the base word katawa with an English transition laugh, katawa inflected with - mag is magkatawa and now has an English transition will laugh.

\section{Table 5}

Morphosemantic Features of Tausug Inflection as Progressive form of the verb

\begin{tabular}{|c|c|c|c|c|c|c|}
\hline $\begin{array}{c}\text { Tausug } \\
\text { Inflection }\end{array}$ & $\begin{array}{c}\text { Tausug Base } \\
\text { Word }\end{array}$ & $\begin{array}{l}\text { With Inflection } \\
\text { Tausug Word }\end{array}$ & $\begin{array}{c}\text { Lexical } \\
\text { Category }\end{array}$ & $\begin{array}{c}\text { Morphological } \\
\text { Process }\end{array}$ & Meaning & Sample Sentence \\
\hline \multirow{11}{*}{$\begin{array}{l}\text {-nag } \\
\text { Inflection }\end{array}$} & $\begin{array}{l}\text { Kaon } \\
\text { (Eat) }\end{array}$ & Nagkaon & Verb (V.) & Prefixation & Eating & $\begin{array}{l}\text { Nagkaon ako sayol iban } \\
\text { say'ing. } \\
\text { I am eating vege-tables and } \\
\text { steamed bananas. }\end{array}$ \\
\hline & $\begin{array}{l}\text { Luto } \\
\text { (Cook) }\end{array}$ & Nagluto & Verb (V.) & Prefixation & Cooking & $\begin{array}{l}\text { Nagluto sila sayol iban say'ing. } \\
\text { They are cooking vege-tables } \\
\text { and steamed bananas. }\end{array}$ \\
\hline & $\begin{array}{l}\text { Hinang } \\
\text { (Work) }\end{array}$ & Naghinang & Verb (V.) & Prefixation & Working & $\begin{array}{l}\text { Nagta-wang sila naghi-nang. } \\
\text { They are working hand in } \\
\text { hand. }\end{array}$ \\
\hline & Lasa & Naglasa & Verb (V.) & Prefixation & Loving & $\begin{array}{l}\text { Naglasa in mga } \\
\text { magtay-manghod. }\end{array}$ \\
\hline & $\begin{array}{l}\text { (Love) } \\
\text { Langoy }\end{array}$ & Naglangoy & Verb (V.) & Prefixation & Swim-ming & $\begin{array}{l}\text { Siblings loving one another. } \\
\text { Nagla-ngoy sila harap pa- } \\
\text { kalawman }\end{array}$ \\
\hline & (Swim) & & & & & $\begin{array}{l}\text { They are swimming into the } \\
\text { deep water. }\end{array}$ \\
\hline & $\begin{array}{l}\text { Labay } \\
\text { (Pass by) }\end{array}$ & Naglabay & Verb (V.) & Prefixation & Passing by & $\begin{array}{l}\text { Naglabay sila ha malagko bay. } \\
\text { They are passing by in the big } \\
\text { house. }\end{array}$ \\
\hline & $\begin{array}{l}\text { Dihil } \\
\text { (Give) }\end{array}$ & Nagdihil & Verb (V.) & Prefixation & Giving & $\begin{array}{l}\text { Nagdihil sila badjo ha mga } \\
\text { bata. } \\
\text { They are giving clothes to the } \\
\text { children. }\end{array}$ \\
\hline & $\begin{array}{l}\text { Lingkat } \\
\text { (Beau- } \\
\text { tiful) }\end{array}$ & Naglingkat & Verb (V.) & Prefixation & $\begin{array}{l}\text { Getting } \\
\text { beautiful }\end{array}$ & $\begin{array}{l}\text { Naglingkat in mga babae ini. } \\
\text { These ladies are getting } \\
\text { beautiful. }\end{array}$ \\
\hline & $\begin{array}{l}\text { Lagko } \\
\text { (Big) }\end{array}$ & Naglagko & Verb (V.) & Prefixation & $\begin{array}{l}\text { Getting } \\
\text { bigger }\end{array}$ & $\begin{array}{l}\text { Naglagko na in mga bata ini. } \\
\text { These children are getting } \\
\text { bigger. }\end{array}$ \\
\hline & Katawa & Nagkatawa & Verb (V.) & Prefixation & Laughing & $\begin{array}{l}\text { Nagka-tawa na adja ako sin } \\
\text { mga bisara mo. } \\
\text { I am just laughing at your } \\
\text { stories. }\end{array}$ \\
\hline
\end{tabular}

The fourth Tausug Inflection is the -nag Inflection. This Tausug Inflection is an inflectional affix, a prefix to be specific, that when inflected in Tausug words will function as a progressive form of the verb. The common Tausug words with -nag inflections are the following: the word nagkaon, from the base word kaon with an English transition eat, kaon inflected with -nag is nagkaon and now has an English transition eating; the word nagluto from the base word luto with English transition cook inflected with -nag will become nagluto and now has an English transition cooking; and the word naghinang from the base word hinang with an English transition work, hinang inflected with -nag is naghinang and now has an English transition working.

Next is the word naglasa, from the base word lasa with an English transition love, lasa inflected with -nag is naglasa and now has an English transition loving. The word naglangoy, from the base word langoy with an English transition swim, langoy inflected with -nag is naglangoy and now has an English transition swimming. The word naglabay, from the base word labay with an English transition pass by, labay inflected with -nag is 
naglabay and now has an English transition passing by. The word nagdihil from the base word dihil with an English transition give, dihil inflected with -nag is nagdihil and now has an English transition giving. The word naglingkat from the base word lingkat with an English transition beautiful, lingkat inflected with -nag is naglingkat and now has an English transition getting beautiful. The word naglagko from the base word lagko with an English transition big, lagko inflected with -nag is naglagko and now has an English transition getting bigger. Lastly, the word nagkatawa from the base word katawa with an English transition laugh, katawa inflected with - nag is nagkatawa, which now means laughing.

\section{Table 6}

Morphosemantic Features of Tausug Inflection as Adjective

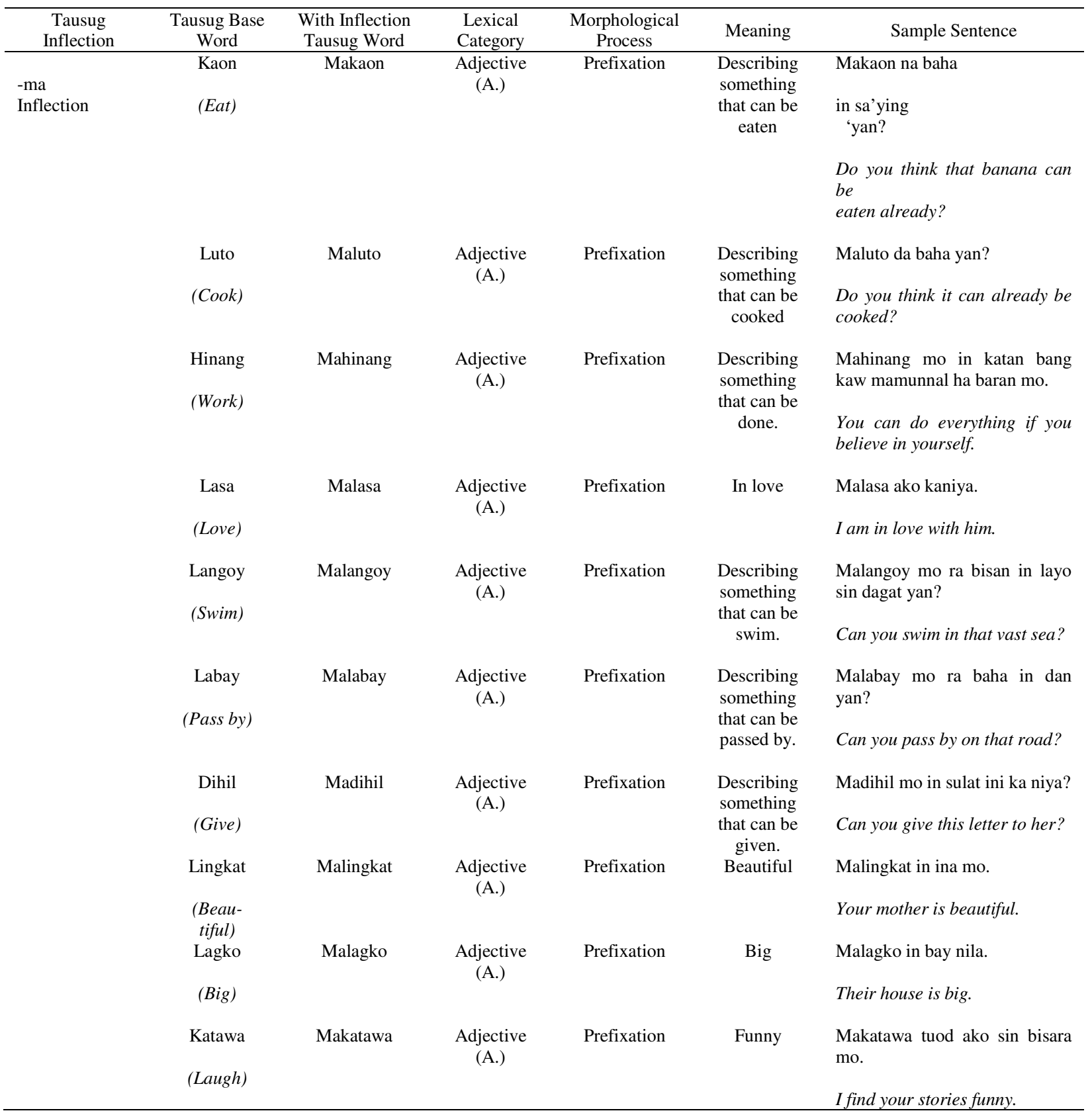

The fifth Tausug Inflection is the -ma Tausug Inflection. This Tausug Inflection is an inflectional affix, a prefix to be specific, that when inflected in Tausug words will function as an adjective. The common Tausug words with -ma inflections are the following: the word makaon, from the base word kaon with an English transition eat, kaon inflected with -ma is makaon which now means describing something that can be eaten; the 
word maluto from the base word luto with English transition cook and when inflected with -ma will become maluto which now means describing something that can be cooked; the word mahinang from the base word hinang with an English transition work, hinang inflected with -ma is mahinang which now means describing something that can be done; and the word malasa, from the base word lasa with an English transition love, lasa inflected with -ma is malasa which now means describing being in love.

Also, the word malangoy, from the base word langoy with an English transition swim, langoy inflected with -ma is malangoy, which now means describing something that can be swim. The word malabay, from the base word labay with an English transition pass by, labay inflected with -ma is malabay which now means describing something that can be passed by. The word madihil from the base word dihil with an English transition give, dihil inflected with -ma is madihil which now means describing something that can be given. The word malingkat from the base word lingkat with an English transition beautiful and functions as a noun, lingkat inflected with -ma is malingkat, which means beautiful and now function as adjective. The word malagko from the base word lagko with an English transition big and functions as a noun, lagko inflected with -ma is malagko which, means big and now function as an adjective. Lastly, the word makatawa from the base word katawa with an English transition laugh, katawa inflected with - ma is makatawa which now means funny.

\subsection{Research Question No. 2: How do the Tausug people preserve their language?}

To answer research question number 2, I conducted in-depth interviews and focused group discussions among 14 participants. I asked five sub-questions to elicit specific and appropriate responses for this research question. The questions asked during the interview were: How often do you use the Tausug language? In what instances do you use it? How would you describe your engagement of the language in terms of writing? What activities in school, at work, or outside your community allow you to use your language? Do you teach the non-speakers to use your language? In what instances do they happen? And what are your initiatives to keep your language alive?

Presented in Table 7 are significant themes and core ideas generated during the interview and group discussion. Participants shared their ways and efforts in preserving their language. From their responses, five major themes emerged: Used at home; Used in written and online communication; Used during occasions; Shared with other cultures; and Encouraged proper usage in Masjid, as presented in Table 7 below.

Table 7

Essential Themes and Core Ideas on How the Tausug people preserve their language

\begin{tabular}{|c|c|}
\hline Essential Theme & Core Ideas \\
\hline Used at home & $\begin{array}{l}\text { Use the language every day at home. } \\
\text { Use the language frequently at home without mixing it with other } \\
\text { languages. } \\
\text { Use the language with relatives or with Tausug people. } \\
\text { Use the language in writing letters to parents, siblings, and relatives. }\end{array}$ \\
\hline Used in written and online communication & $\begin{array}{l}\text { Use the language in sending messages through chat and text to Tausug } \\
\text { people. } \\
\text { Use the language in Tausug weddings. }\end{array}$ \\
\hline Used during occasions & $\begin{array}{l}\text { Follow the tradition and culture of Tausug and speak the language during } \\
\text { gatherings. } \\
\text { Teach the language to the Bisaya if they would like to. }\end{array}$ \\
\hline Shared with other cultures & $\begin{array}{l}\text { Teach Bisaya friends, classmates, and co-workers of Tausug words. } \\
\text { Reprimand Tausug relatives who are not using the language inside the }\end{array}$ \\
\hline Encouraged proper usage in Masjid & $\begin{array}{l}\text { Masjid. } \\
\text { Teach the Tausug people correct pronunciation and usage of the Tausug } \\
\text { language inside the Masjid. }\end{array}$ \\
\hline
\end{tabular}

Used at home - The study revealed that the Tausug people preserve their language through frequent use at home. This finding is confirmed by one of the participants as he discussed that for the Tausug native not to forget their language, they should use the language fluently and solely inside their home.

"Ha lawom bay, in bisara, in bisara ta amo ra man jud, di ta kalamuran dugaing." (IDI-001) 
(At home, the language we should use is purely Tausug. We should not mix the Tausug language with other languages.)

This is supported by 074UE (pseudonym), where he emphasized his efforts in using the Tausug language. He said that he is using the language with his family and relatives at home. He made sure to use the language with Tausug people who can understand the Tausug language.

"Ha lawom bay, mawmu namo giyagamit in Bahasa Tausug. Bang in iban ko magbisara Tausug, makahati Tausug, taptap ko giyagamit in Bahasa Tausug. Mga anak ko, ha lawom bay, hisiyo-siyo na lasya ko, Tausug sadja in giyagamit ko Bahasa.” (IDI-007)

(Inside our home, we frequently use the Tausug language. I am using the language if I am with Tausug or who can understand Tausug, like with my children and my relatives. Inside our home, I always use the Tausug language.)

Moreover, 072BM (pseudonym) shared the same thoughts in preserving the Tausug language. The participant revealed that she is using the Tausug most of the time if she talks to her relatives or any Tausug people at home.

"Paggamiton ko in Bahasa Tausug bang ako ha bay, awon iban ko na magbisara Tausug iban daran ko siya giyagamit." (FGD-001)

(I am using the Tausug language if at home, and I am talking with Tausug people. Most of the time, I am using the language.)

Used in written and online communication - During the interviews and discussions, participants revealed that one of their efforts in preserving their language is using it in written and online communication. From sending letters and now sending messages through modern communication such as texting and chatting, participants have been using this almost every day. As one of the participants of the study shared, she was using the Tausug language is sending letters to her family and relatives here in the Philippines when she was working abroad.

“Bang Tausug, Tausug (bang magpara sulat). Bisan ha abroad ako, sulat ko mari, Tausug.” (IDI-001)

(If it is for the Tausug people, I will use it in sending letters. When working abroad, I used the Tausug language whenever I sent letters to my family in the Philippines.)

One of the participants supported this claim as she has the same experience while working abroad. This participant was also using the Tausug language in writing letters to her parents and siblings here in the Philippines.

"Siyempre magpara kaw sulat mari pa maas mo, taymanghod mo, Tausug ra isab in isulat mo, biyahadto, para isab sila makahati.” IDI-002.

(When you will give letters to your parents and siblings, you use the Tausug language for them to understand your letter.)

On the other hand, in today's generation, Tausug natives use the Tausug language in writing using modern communication. Online communication, like sending messages in messenger, has been one of the trends nowadays. Hence, Tausug natives are using their language in using this kind of communication. 072BM (pseudonym) supported this notion when she shared that she is using the Tausug language in chatting with Tausug people.

"Huon, paggamiton ko siya bang kailangan ko isab. Bang in ka chat ko tausug isab, Tausug isab in gamiton ko.” (FGD-001)

78 Consortia Academia Publishing (A partner of Network of Professional Researchers and Educators) 
(Yes, I am using the language in writing if necessary. Also, if I am chatting using a messenger application with Tausug, then I will use the Tausug language.)

This notion is also supported by one of the participants as she said that she is using the Tausug language when she will send texts or chat with her siblings who are living in another area.

“Na Tausug bang awon ka chat ko, o mag text, o mag kuan labi na ha mga taymanghod ko, malayo.” (FGD-007)

(Yes, I use the Tausug language if I have someone to chat or text, primarily my siblings who live in another place.)

Used during occasions - The interviews revealed that attending occasions like wedding allow the participants to use their language. As one of the participants discussed in the interview, she is using the Tausug language whenever she will attend a Tausug wedding or in any Tausug gatherings.

"Sawpama manlurok kita pagtiyaon Tausug, Tausug ra isab. Magsambahayang pa masjid o awon mga okasyon, magpunpun in Tausug. Katan okasyon, biya magkurambos, basta magpunpun in Tausug, Tausug ra man isab in giyagamit ta.” (IDI-001)

(For instance, I will be attending a Tausug wedding, I always use the language. Also, I always use the language whenever I go to Masjid (Islam's Church) or even at Tausug gatherings. On any Tausug traditional occasions, there is no other language I will use other than the Tausug language.)

This is supported by 056BA (pseudonym) as she emphasized the significance of using the Tausug language on Tausug occasions and following the Tausug tradition.

"Pagtiyaon, gamiton ta ra in Bahasa ta, bisara ta, in lihok ta Tausug. Hinang uno katan amo ra (harap pa kawman). Kay amo man in bisara ta, alang-alang, Tausug in bisara ta.” (IDI-003)

(At weddings, we must also use our language and follow our tradition. Anything you do during gatherings of the Tausug tribe, you must use our language because it is our own.)

One of the participants also shared the same idea as he revealed his experience in attending a Tausug wedding.

“Magamit ta siya, bang kita sawpama, manlurok or awon pag imon-imon, mga party. So duon kita makagamit, ha lawung niya ha kawman, bang mang guwa-guwa kita pa tao, pa kawmna Tausug sawpama biya Tambongon yadto, gumuwa kita, didto kita makagamit sin bahasa ta, bang isab Tausug ra in mada ta magbisara." (IDI-006)

(We can use it if we will attend weddings, gatherings, or parties. We can use the language if we go outside our community or to other places, like Tambongon. We can use the Tausug language when we go there, since there are many Tausug in that area.)

Shared with other cultures - The study found out that Tausug natives shared their culture and tradition with other groups and tribes. One of the participants said that she is teaching her Bisaya friends the Tausug language.

“Awon. Ha maccam yan, mga Bisaya magkawon yan. Bang awon bisara ko Tausug duon ha mga bata, hi bayta ko kanila, kawaa yadto, kuhaa daw to. Amon nag-ingka ingka yadto... min.ana diay te, aron dili mo makaingon na gilibak mo." (IDI -001)

(I have Bisaya friends who frequently come to Maccam (Tausug sacred/prayer place). Whenever I talked to my grandchildren using the Tausug language, I always translated it for them in Bisaya, 
for instance, "Kawaa yadto" which is in Bisaya, "Kuhaa daw to" for them not to think that we are insulting them.)

This is supported by one of the participants as she discussed her experience with her friends who are curious about the Tausug language and asking her about the meanings of some Tausug words.

"Biya kako ha paghinang biyahayan mangasuwo bang uno in meaning sin biyahan, amo yan, makatudlo ako kanila (ha mga Tausug na di na maingat magbisara). Amo ra giyapon, magpahindo bang uno in meaning sin biyaini (ha mga Bisaya).” (FGD-006)

(Just like me, when I am at work, they will ask about the meaning of certain Tausug words then I will answer them (for Tausug people who do not know their language anymore). Also, I will teach them if they ask about the meaning of certain Tausug words (for her Bisaya friends).

Moreover, 013AD (pseudonym) supported this with her experience in school. She stated that her classmates and friends were asking her about the meaning of some Tausug words.

"Kako isab mataod na ako yan, mga classmate ko nakauna or ha paghinangan bang uno kuno in meaning sin malingkat. Amon mga simple na word sadja, gwapa kanila, malingkat kato. Amon mga kabayaan nila kaingatan kay curious man isab sila kato, sin language ta." (FGD-005)

(For me, I also experienced at work or at school where my Bisaya friends would ask me, for instance, the meaning of "malingkat" (beautiful). Those simple Tausug words they want to know, like what is malingkat or gwapa. They are also curious about our language.)

Encouraged proper usage in Masjid - The study revealed that the natives of Tausug are particular in using their language correctly and appropriately. Among their efforts is encouraging the Tausug people to properly use the Tausug language in Masjid (Tausug term in their church). As one of the participants revealed:

"Na in amon sawpama in bukon magbi-bisara Tausug, hinduan ta pa bisara ta, batsa di malawa in bisara ta Tausug. Sawpama kita Tausug, magbisara ha lawum masjid Bisaya, na langon ta, bang manjari kay Karapatan ta in kita mag addat kita ha bisara ta, pag addatan ta in bisara ta, di ta gamiton amon lawung sa Tausug kita iban sakali mag Bisaya kita, amo yadto in mahunit, na lumugay malawa na in bisara ta bang ta di gamiton, labi na ha lawum masjid.” (IDI-002)

(For those Tausug who is not speaking the language, let us teach them not to forget it. As a Tausug, if we are in the Masjid, then someone is speaking using Bisaya. Let us reprimand them because it is our responsibility to respect our language. We must use it in the Tausug group; it will be difficult if we keep using the other languages, especially if we are in the Masjid because we might forget our language.)

It is supported by 056BA (pseudonym) as she emphasized her efforts in encouraging the Tausug people to use the language properly.

"Huon, magsagda ra isab ako. Bisan uno wakto bang awon nagbisara, bisan ha lawom langgal, abi na bisara Bisaya, "Ai, mayta magbisaya kamo sin yari kamo ha lawom langgal. Bisara ta, Tausug in bisara ta kay Tausug kita.” (IDI-003)

(Yes, I am also teaching them. Anytime if there is Tausug who is not using the Tausug language, especially in Masjid, I would say, "Why are you using the Bisaya when you are here in Masjid? Our language is Tausug because we are Tausug, and we must use it.”)

Also, 095UI revealed that the Tausug language would not be extinct. Tausug people should use the language properly wherever or whenever they are, primarily in Masjid.

80 Consortia Academia Publishing (A partner of Network of Professional Researchers and Educators) 
"Bang ha guwa sin kawman, bang uno in bisara, amo ra. Bang pagtiyaon, bang Tausug, Tausug ra in gamiton ha mga mada magbisara. Bang ha masjid, magsambahayang kaw, amo ra Tausug ra in gamiton." (IDI-005)

(Whatever your language and when you are outside the community, then always use that language. When there are Tausug weddings and talking to Tausug there, then use the Tausug language. When in Masjid, it is the same, use the Tausug language.

4.3 Research Question No. 3: What are the insights of the Tausug ethnic group on the importance of the language in their cultural identity?

For research question number 3, I conducted in-depth interviews and focus group discussions among 14 participants. Similarly, I asked five sub-questions to elicit specific and appropriate responses for this research question. The questions asked during the interview were: What are the experiences that motivate you to use your language? What are the experiences that demotivate you to use it? What should the non-speakers and speakers learn from such experiences you have encountered? What are your roles as a native speaker to encourage the younger generation to use your language? And what are your thoughts and perception that your native language is being explored in this research?

Participants revealed their insights on the importance of the language in their cultural identity. Presented in Table 8 are significant themes and core ideas that prevailed during the interview and group discussion. The study revealed four major themes, namely: Deeply rooted in the culture; Sense of cultural pride; Conflict of language during conversation; and Importance of research for preservation, as presented in Table 8 below.

\section{Table 8}

Essential Themes and Core Ideas on What are the insights of the Tausug ethnic group on the importance of the language in their cultural identity

\begin{tabular}{|c|c|}
\hline Essential Themes & Core Ideas \\
\hline Deeply rooted in the culture & $\begin{array}{l}\text { Have been using the language from birth until now. } \\
\text { Tausug language was taught by the parents and elders. } \\
\text { Not ashamed to use the language outside the community. }\end{array}$ \\
\hline Sense of cultural pride & $\begin{array}{l}\text { Proud of the Tausug tribe and will use the language everywhere. } \\
\text { Show everyone the culture and tradition of the Tausug people. } \\
\text { Use the Bisaya language to talk with Bisava people to understand one }\end{array}$ \\
\hline Conflict of language during a conversation & $\begin{array}{l}\text { another. } \\
\text { Proud that the Tausug language is being analyzed. } \\
\text { An opportunity to propagate and share the Tausug language. }\end{array}$ \\
\hline Importance of research for preservation & Encourages the Tausug people to use their language. \\
\hline
\end{tabular}

Deeply rooted in the culture - The interviews prevailed that the Tausug natives are using their language, for it is deeply rooted in them from birth until now. It is evident how they value their culture as 058BG (pseudonym) said that the Tausug language, as well as the values of being Tausug, had been imparted to them by their parents.

"Na siyempre uno in piyabulat sin maas mo kaymo, bang uno in bisara sin maas mo kaymo,
sampay pa anak mo, yan mara na. bang uno in kita mo ha maas mo, bang uni in piyahati sin
maas mo biyahadto, orientation sin maas mo, hindu kaymo sin maas mo, daying ha kaapo-apoan,
amo ra in mara sin anak pa apo." (IDI-002)

(From the moment you were born, the language of your parents will be imparted to you and your children. What you see from your parents and their values will be applied to you. Also, their orientation will be passed on to you until to your grandchildren.)

This experience is supported by $084 \mathrm{BH}$ (pseudonym) as she stated:

"Tausug in Bahasa giyagamit ko daying ha pagka bugsak ko ha sikahan, nakaingat na ako, 
awon na ako pangannal, in kiyadungugan ko Tausug isab na amo na hadja iyan in giyagamit ko, kami di ha lawom bay Tausug, bang na ha panawan bang Tausug in kabisara ko na tausug na hadja.” (FGD-003)

(I am using the Tausug language from the moment I was born and knew things. When I understand the world, this is the language I first heard and used. In our home, we are using the Tausug language. When going outside and whenever there are Tausug, I talk to them using the language.)

013BR (pseudonym) also stated that:

"In ako, nagamit ko in Tausug daying ha pagpalaggo sin maas ko. Amo in language kiyaingatan ta ha pagpanganak kato di ha dunya, pag tudlo sin maas ta ha lawom bay, amo in language kiyaingatan nato iban usahay mag Bisaya na kita kay amo naman yari na kita naka agad ha mga Christian. Pero bang kita nakakadto pa dugaing hula ha mga ka tausugan tuod biya isab kita maluman kay di man kita makahati sin bisara nila, awon man malawom bisara nila na isab sila mag atod isab sila kato pero amo naman in kiyamatahan sin mata ta amo na in pagbisara ta, amo na isab in dahan ta, ikaduwa na kaywanan.” (FGD-005)

(For me, I use the Tausug language because this is how I was raised by my parents. This is the language we knew when we were born and what our parents taught us inside our home, although sometimes we use Bisaya because we are in the community of Christians. Whenever we go to the Tausug community, we are sometimes embarrassed because we tend to forget some of the Tausug words that have a deeper meaning. But since we are living here with the Bisaya, then we evolve and adapt their ways of using the language. Bisaya became our second language.)

Further, one of the participants stressed her reason of using the Tausug language as she said:

"Ako, amo ra isab. Amo na in kiyadungogan ko daying pag-anak kako, paglaggo ko, nag iskol ako, amo na in kadungogan mo Tausug, Tausug ra isab in bisara.” (FGD-007)

(I also use the Tausug language because this is what I heard from the day I was born, growing up, and when I went to school; thus, I am using the language.)

Sense of cultural pride - Sense of cultural pride also prevailed during the interviews as the participants shared their insights on the importance of the Tausug language in their cultural identity. One of the participants emphasized that he is not embarrassed by using the Tausug language outside their community or when he is with the Bisaya group.

"Di ako maluman maggamit sin Bahasa nato (in instances where they are only two of them who are Tausug). Bang sawpama duwa-duwa namo ra nagbissara, Tausug in gamiton ko. Sa bang sawpama awon Bisaya nakadungog, na Bisaya in gamiton ko batsa in ha raig namo mga Bisaya makahati bang uno in piyagbisarahan namo." (IDI-007)

(I am not ashamed to use our language. If we are the only Tausug among the other tribes/groups, I will still use the language. But if there are Bisaya who are listening to our conversation and want to understand what we are talking about, then I will use the Bisaya.)

Another participant highlighted her thoughts of being proud of using the Tausug language and its culture.

"Wayroon isab kay ako Tausug man ako. Dahon ko siya magbisara Tausug kay Tausug siya, Tausug ako, mayta ako maluman, sali man in bangsa namo? (Bang awon siya kakitaan Tausug ha lawom sin kabisayaan).” (FGD-001) 
(There are no instances because I am Tausug. I will talk to them using the language if they are Tausug. I am Tausug, so why would I be ashamed when we are both Tausug? (This is for those Tausug people she will meet in the Bisaya area).

This is supported by $012 \mathrm{BB}$ (pseudonym) as she stated:

"Ako bang ha iskulan amon awon ako kakitaan or ha dugaing biya ha guwa sin bay ba kakitaan ko Tausug bisan yadto ako ha lawman sin kabisayaan mag Tausug ra isab ako. Di, iban ha iskulan nakaingat ra man sila na Tausug ako, lawung gani nila Korean in bisara ta (Di niya ikaluman magbisara Tausug ha lawum kabisayaan)." (FGD-004)

(When I am at school or meet someone outside who is Tausug, even if I am with Bisaya, I will still use the Tausug language. I am not ashamed because they already know that I am Tausug, and for them, they think our language sounds like Korean (she is not embarrassed to use the Tausug language when she is with her Bisaya friends at school).

Conflict of language during a conversation - The study also revealed that the difficulties of Tausug people in using the language outside their community is living with other groups, the Bisaya. The participants tend to use their language in talking to them instead of Tausug for them to understand one another.

"Biya biyaan, amon wala sa sabab na di ako ganahan pero awon man jud time na di kaw makagamit yan labi na Bisaya in kabisara mo mag Tausug lang giyapon kaw bisan di kaw kahatihan biyahan. Way jud sabab, awon lang time na di kaw makagamit kay yari man kita ha lawom kabisayaan." (FGD-006)

(Some things demotivate me to use the Tausug language because there are times when you cannot use the language, especially when you are talking to Bisaya. It will be useless if you still insist on using the Tausug language when they cannot understand you. I am not demotivated. There are just times when you cannot use the Tausug language because we are in the area of Bisaya.)

This was also revealed in the experience of 084BN (pseudonym) as she stated:

"Ako isab, di ko siya magamit labi na in kabisara ko labi na ako nakapa dugaing hula, in bisara nila na di ko magamit in Bahasa Tausug kay in bisara nila, bisara didto (ha waktu na yadto siya naghinang ha abroad). Bang isab awon ka bisara ko di ha pinas na mag Tausug ako, magamit ko ra isab.” (FGD-007)

(For me, I cannot use the language when I am talking to other people, especially when I was working abroad; then I adapted their language and could not use the Tausug language. But when I spoke to my family and friends here in the Philippines, I used the Tausug language.)

Moreover, 007BD (pseudonym) highlighted his thoughts of having a language conflict with other groups or tribes during a conversation.

"Bukon di kita gumamit sin bahasa tausug kay in kabayaan ta, gamiton ta tuod in bahasa Tausug. Sa bang kita isab ha tumpukan sin Bisaya, para kita makahati, in gamiton ta kanila kay para magsabot. In ikahunit dayndion bang sila mari kato ampa di sila makasabot, na suway sila maguro." (IDI-004)

(It is not that we do not like to use the Tausug language, but for us to understand one another when talking to the Bisaya, we will use the Bisaya. However, if they will go to the community of Tausug and they cannot understand the language, then they should ask the community to teach them.) 
Importance of research for preservation - The interviews revealed the insights of the Tausug natives on the importance of research in preserving their language. One of the participants discussed the significance of the study in encouraging the Tausug people who are not using the language anymore to relearn it and not be ashamed of using the language.

"Na malagko in katatawangan sin pagpangadji niyo yan pasalan sin Bahasa Tausug pasalan muna-muna in tao maluman gumamit sin bahasa niya, magamit niya na, di na siya lumuman pasalan na awon na ha community, na awon na ha biya kaniyo nangangadji. Hati niya in lalahungan sin Tausug, liyalagko ra isab, ini magamit ra isab pa makatauran ha makahati sin Tausug, malaggo siya yadto ikatawang." (IDI-007)

(Then your study will be a great help to encourage those Tausug people who are ashamed to use their language. They will not be ashamed because it is already known by the community. It means that the roots of Tausug develop and flourish by everyone. Those who can understand the language can be a great help to keep it.)

This is supported by 042BL (pseudonym) as she said that research could be a good reference for those who would like to learn the Tausug language.

"Maka proud and malingkat siya kay at least diba ha awon mabaya makaingat mag Tausug awon na sila reference na awon na diay nag study ha ini so malingkat pod diay in tausug." (FGD-002)

(I am proud. This is a good endeavor because for those who want to learn our language, they can have a reference since there is someone who studied about it.)

The study also revealed the participant's experience on the importance of research in propagating and sharing the Tausug language with everyone. She quoted:

"Ini in pangadji ini ha Bahasa Tausug malaggo ini siya chance, opportunity para kato mga Tausug na mas mapalawak pa ba, mapasaplag in Bahasa ta. Huon bunnal hi Ina (FGD 3) hangkatiyo ra baya jud in nag reresearch tungkol ini iban pag maingatan nila na awon na diay nag reresearch ini, iban makuan isab in kaywanan ba biya ma curious na biyaini diay in Bahasa Tausug (Na bisan pa bukon Tausug makaingat sin Bahasa Tausug daying ha pangadji ini).” (FGD-004)

(This study about the Tausug language is a great chance and opportunity for us Tausug to propagate and share our language. Yes, Ina (FGD 3) is right that there are only a few who are interested in studying our language. If they know that there are studies about it, then it can catch their curiosity to understand our language (So even if non-speakers will learn the language because of this study).

\section{Discussions}

The primary purpose of this study is for the preservation of native languages, specifically the Tausug language. This research is one way of documenting the analysis of the Tausug Inflection and the efforts of Tausug natives in protecting it. United Language Group (2021) identified ways of preserving native languages, and among these is through translation, localization, and interpreting, which I applied in this research to analyze the morphosemantic features of Tausug Inflection.

On the other hand, insights of the Tausug ethnic group on the importance of their language in their cultural identity were also delved into the study. After analyzing the morphosemantic analysis of Tausug Inflection, it is also essential to know how language affects the cultural identity of the Tausug natives. Rovira (2008) defined 
cultural identity as a system of beliefs of a group of people transfers from the older generation up to now. $\mathrm{He}$ also emphasized the importance of language in cultural identity. According to him, language is essential in cultural identity, and it allows the transfer of culture and beliefs of ones' tribe from generation to generation.

Moreover, in the theory of Edward Sapir and Benjamin Lee Whorf, the Sapir-Whorf Hypothesis, which is the central theory of this study, language is defined as an essential part of knowing and understanding the culture and tradition of the natives. Hence, analyzing the morphosemantic features of Tausug Inflection allow us to understand their ways and behavior. Also, this analysis would show the efforts of the Tausug in preserving their native tongue and maintaining cultural identity.

In line with these, I invited 14 participants to share their perspectives and insights in preserving their language and maintaining cultural identity in this fast-changing environment. Seven of these participants shared their thoughts in an in-depth interview, while the other seven is in focus group discussions. These participants were all natives of the Tausug tribe in Barangay Hijo, Municipality of Maco, Province of Davao de Oro. Moreover, these participants are all well-versed with their language and still practice their culture and tradition.

Morphosemantic features of Tausug Inflection. In analyzing the morphosemantic features of the Tausug language, I asked the participants to list down the common Tausug words they are using every day. From those words, I instructed them to list down other words they can construct using Inflection. As one of the natives of the Tausug tribe and with the helped of my debriefer which is one of the elders in the community, I was able to analyze the morphosemantic features of Tausug Inflection. From the Tausug words given by the participants, there was five main Tausug Inflection that emerged.

The first Tausug Inflection is -um Inflection. This Inflection is used in Tausug words as infix and would make the words function as an infinitive verb, the to $+v e r b$. This Tausug Inflection is usually used in Tausug words that function as verbs. The Tausug word kaon, which means eat, can be inflected with -um as such $k+u m+a o n$ become kumaon, which now means to eat.

Other common Tausug words with -um inflection are luto with English transition cook when inflected with -um inflection as such $l+u m+u t o$ become lumuto and now has an English transition to cook; hinang with an English transition work when inflected with -um inflection as such $h+u m+$ inang become huminang which now means to work; lasa with an English transition love when inflected with -um inflection as such l+um+asa become lumasa and now has an English transition to love; langoy with an English transition swim when inflected with -um inflection as such $l+$ um+angoy become lumangoy which now means to swim; labay with an English transition pass by when inflected with -um as such $l+u m+$ abay become lumabay which now means to pass by; dihil with an English transition give when inflected with -um as such $d+u m+i h i l$ become dumihil and now has an English transition to give; lingkat with an English transition beautiful, lingkat when inflected with -um inflection as such $l+u m+$ ingkat become lumingkat which now means to love; lagko with an English transition big, when inflected with -um inflection as such l+um+agko become lumagko which now means to get bigger; and lastly katawa when inflected with -um inflection as such $k+u m+$ atawa become kumatawa which now means to laugh.

The second Tausug Inflection is -im inflection. This Inflection is used in Tausug words as infix and would make the words function as the past tense of the verb. This Tausug Inflection is usually used in Tausug words that function as verbs. With the same Tausug words given by the participants, the meaning of these words changes when inflected with -im inflection. The Tausug word kaon presented earlier when inflected with -im will become kimaon from $k+i m+a o n$, which now means ate.

The same with Tausug words luto with English transition cook when inflected with -im will become limuto from l+im+uto which now means cooked; hinang with an English transition work, when inflected with -im is himinang from h+im+inang which now means worked; lasa with an English transition love, when inflected with -im is limasa from l+im+asa which now means loved; langoy with an English transition swim, inflected with -im is limangoy from $l+i m+$ angoy which now means swam; labay with an English transition pass by, when inflected 
with -im is limabay from $l+i m+a b a y$ which now means passed by; dihil with an English transition give, when inflected with -im is dimihil from $d+i m+i h i l$ which now means gave; lingkat with an English transition beautiful, when inflected with -im is limingkat from l+im+ingkat which now means got beautiful; lagko with an English transition big, when inflected with -im is limagko from $l+i m+a g k o$ which now means got bigger; and lastly katawa with an English transition laugh, when inflected with -im is kimatawa from k+im+atawa which now means laughed.

The third Tausug Inflection is -mag inflection. This Inflection is used in Tausug words as a prefix. When Tausug words are inflected with -mag, they mean things you want to do in the future; as such, the -mag inflection when use will have a modal verb will. With the same words presented, -mag inflection will create a new meaning for those words. The Tausug word kaon with an English transition eat, when inflected with -mag is magkaon from mag+kaon, which now means will eat.

The same with Tausug words luto with English transition cook, when inflected with -mag will become magluto from mag+luto which now means will cook; hinang with an English transition work, when inflected with -mag is maghinang from mag+hinang which now means will work; lasa with an English transition love, when inflected with -mag is maglasa from mag+lasa which now means will love; langoy with an English transition swim, when inflected with -mag is maglangoy from mag+langoy which now means will swim; labay with an English transition pass by, when inflected with -mag is maglabay from mag+labay which now means will pass by; dihil with an English transition give, inflected with -mag is magdihil from mag +dihil which now means will gave; lingkat with an English transition beautiful, when inflected with -mag is maglingkat but the initial consonant of the stem lingkat should be reduplicated to make the word correct and appropriate to use as future form of the verb, thus maglingkat should be maglilingkat from mag+li+lingkat which now means will be beautiful; also with the word lagko with an English transition big, when inflected with -mag is maglagko but the initial consonant of the stem lagko should be reduplicated to make the word correct and appropriate to use as future form of the verb, thus maglagko should be maglalagko from mag+la+lagko which now means will get bigger; and lastly katawa with an English transition laugh, when inflected with - mag is magkatawa from mag + katawa which now means will laugh. The two Tausug base words lingkat, and lagko, are used as nouns in the Tausug language; hence, if nouns will be inflected with -mag, the initial consonant of the stem is reduplicated to make it more appropriate to use.

The fourth Tausug Inflection is -nag inflection. This Inflection is used in Tausug words as a prefix and would make the words function as a progressive form of the verb. With the same words presented, -mag inflection will also give new meanings for those words. The Tausug word kaon with an English transition eat when inflected with -nag is nagkaon from nag+kaon, which now means eating.

The same with Tausug words luto with English transition cook, when inflected with -nag will become nagluto from nag+luto which now means cooking; hinang with an English transition work, when inflected with -nag is naghinang from nag + hinang which now means working; lasa with an English transition love, when inflected with -nag is naglasa from nag +lasa which now means loving; langoy with an English transition swim, when inflected with -nag is naglangoy from nag+langoy which now means swimming; labay with an English transition pass by, when inflected with -nag is naglabay from nag+labay which now means passing by; dihil with an English transition give, inflected with -nag is nagdihil from nag + dihil which now means giving; lingkat with an English transition beautiful, when inflected with -nag is naglingkat from nag+lingkat which now means getting beautiful; lagko with an English transition big, when inflected with -nag is naglagko from nag+lagko which now means getting bigger; and lastly katawa with an English transition laugh, when inflected with - nag is nagkatawa from nag+katawa which now means laughing.

The fifth Tausug Inflection is -ma inflection. This Inflection is used in Tausug words as a prefix and would make the words function as adjectives. Just like the four inflections discussed above, with the same Tausug words, -ma inflection also gives new meaning to those words. The Tausug word kaon with an English transition 
Hatihun nato: A morphosemantic analysis of Tausug inflection

eat when inflected with -ma is makaon from ma+kaon which now means describing something that can be eaten.

The same with Tausug words luto with English transition cook, when inflected with -ma will become maluto from ma+luto which now means describing something that can be cooked; hinang with an English transition work, when inflected with -ma is mahinang from ma+ hinang which now means describing something that can be done; lasa with an English transition love, when inflected with -ma is malasa from ma+lasa which now means describing being in love; langoy with an English transition swim, when inflected with -ma is malangoy from ma+langoy which now means describing something that can be swam; labay with an English transition pass by, when inflected with -ma is malabay from ma+labay which now means describing something that can be passed by.; dihil with an English transition give, inflected with -ma is madihil from ma+dihil which now means describing something that can be given; lingkat with an English transition beautiful and function as noun, when inflected with -ma is malingkat from ma+lingkat which still means beautiful but function as adjective; lagko with an English transition big and function as noun, when inflected with -ma is malagko from ma+lagko which still means big but function as adjective; and lastly katawa with an English transition laugh, when inflected with - ma is makatawa from ma+katawa which now means funny.

How the Tausug people preserve their language. This research generated five essential themes to know the efforts of the Tausug people in keeping their language. The first essential theme that prevailed is Used at home. Based on the result of this study, participants preserve their language by using it frequently at their homes. Tausug natives make sure to speak their language fluently, especially at home. This is supported by Calderon (2020) that the Tausug tribe taught their literary stories through oral tradition. Hence, using their language at home was practiced and propagated through their elders' telling stories to the tribe. Gladly even today, in our community, this practice continues for the younger generations.

Also, Talking is Teaching Organization (2020) supported this finding as they highlighted the importance of using the language at home. Using the native language every day at home is the first step in teaching it to the child and use it effectively. They also stated the importance of having a solid foundation of native language in learning other languages. More so, Intercultural Developmental Research Association (2000) agreed to this notion as they highlighted the importance of maintaining the native language. According to them, the native language of one's child is imperative in maintaining their identity. The use of native language frequently at home or outside the community can be beneficial in the personal, social, intellectual, educational, and economic aspects of a child. Moreover, the role of parents and elders is essential in teaching the native language to the child and instilling to them the significance of using their language.

The second essential theme that emerged is Used in written and online communication. Participants revealed that they use the Tausug language in writing letters and sending messages through text and chat. Parallel to the study of Galla (2009), he explored the importance of technology in preserving indigenous languages. Communicating using the technology allow speakers to utilize the different modes of communication online that play a role in keeping indigenous languages. Amos (2012) supported this finding as he mentioned that globalization has been the main reason for language extinction, but it can be the solution to save these languages through modern technology. The use of social media like Facebook can be a great tool in preserving native languages through engaging and amplifying the voice and existence of the natives. Sending messages through text connects people and allows the natives to use and connect their language with their language.

Furthermore, Villa (2002) conducted a research study parallel to the research's finding entitled Integrating Technology into Minority Language Preservation and Teaching Efforts: An Inside Job. This research described the implication of computers in preserving native languages. The use of technology like computers can be used to develop a system to keep native languages more cheaply. Hence today, sending messages through messenger is convenient and affordable for the natives to reach out to their relatives from other regions and towns. The Tausug natives were using their language in utilizing these technological devices. 
The third essential theme that emerged is Used during occasions. According to the participants' responses, using the Tausug language during occasions and gatherings allows them to be fluent in their native tongue. Speaking the language with their Tausug relatives on special occasions strengthens the involvement of the natives in preserving their language. Tausug Familiarization Course (2020) supported this theme as they described Tausug riddles or tigum-tigum, which serve as entertainment and often perform during weddings and wakes and during Ramadan. This kind of activity allows the Tausug natives to use their language during these occasions and develop social interaction.

Encyclopedia Britannica (2021) conformed to this finding as they discussed the significance of society in language. As stated, language is developed in society, and social settings significantly affect the transmission of language. Elders may teach, correct, and encourage the younger generation to speak using their native language in a social setting. Moreover, the culture and tradition of Tausug natives are flourishes through social gatherings. Attending Tausug weddings allow us, the natives wear our traditional clothes and follow our culture. Most importantly, this social occasion will enable us to speak our language. Parallel to the study of Soto (2021) about preserving language and culture, he stated that having a solid foundation of maintaining culture and language is essential in passing them on to the younger generation. Elders play as a reference for the new generation in learning their culture and language. Using the language with them and listening to their teaching allows them to be close with their heritage.

The fourth essential theme that emerged is Shared with other cultures. Participants shared their experiences of using their language with different cultures or groups like the Bisaya. They revealed from their responses that their friends and acquaintances from other groups are curious and wanted to learn their language. Old Dominion University (2020) agreed to this finding as they enumerated actions by the United Nations members in protecting and preserving Indigenous languages. One of these actions is creating an avenue in sharing the beauty of the culture, tradition, and language of indigenous people to promote the preservation of language. Further, Amin and Shahid (2013) conducted a case study about the influence of language on knowledge sharing among the Pakistani workers in selected Swedish multinational companies that supported the finding. According to their research, the diverse language of the employees in organizations influences the business abilities and activities of a certain company. However, it is essential in the innovation and application of ideas among the employees the sharing knowledge through social interaction and identifying a medium of communication.

In terms of the business environment, it is an important skill to work cooperatively and creatively with other people who have different cultures. Parallel to the article of Blanding (2012), he interviewed Roy Chua, a professor, about his insights into the diverse cultures in a working environment. Chua mentioned that cultural diversity entices innovation and creativity produces through the recombination of existing ideas. On the other hand, to minimize misunderstanding of having a different cultural background, everyone must find a common goal that would benefit everyone.

Lastly, the fifth essential theme that emerged is Encouraged proper usage in Masjid. Participants revealed that they preserve their language by using it correctly and properly with the guidance of their elders. This finding is supported by Jubilado, Ingilan, and Dumanig (2015) that the language of Tausug is anchored to the teaching of Islam. For the Muslim speakers of this language, Islam is a way of life that goes strongly with the observance of adat, the customary laws. Hence, profanity among speakers of Bahasa Sug is sanctioned by the Islamic faith and declared haram or religiously forbidden. With this, elders of the Tausug community make sure that the younger generations are using the language appropriately and correctly, specifically inside their Masjid. Frey (2016) agreed to this finding as he stated in his article that the teaching of native languages to younger generations benefits the preservation of language. In this teaching and learning process, elders play a significant role. Elders have the responsibility to reprimand the new generation if they are misusing the language.

Similarly, in the article of Rogers (2020), she discussed the implication of saving the indigenous languages and preserving cultures. Her article examined the new translation of Jicarilla Apache texts and tribes that lived in 
the deserts and mountains of Arizona and New Mexico and the plains of southern Colorado, with some smaller tribes extending into present-day Oklahoma and Texas. According to her, elders play a vital role in re-translating indigenous languages collected years ago and translated for updated and accurate translations. This effort will help the younger generation learn the language accurately and adequately.

Insights of the Tausug ethnic group on the importance of the language in their cultural identity. After analyzing the data of this study, I generated essential themes that emerged from the insights of the Tausug ethnic group on the importance of language in their cultural identity. The first essential theme is Deeply rooted in the culture. Based on the data analysis, participants revealed that learning the Tausug language started from their birth and shapes their values as they grow. This finding is supported by Mercuri (2012) as he explained in his research how language shaped the identity of an individual. In his study Understanding the Interconnectedness between Language Choices, Cultural Identity Construction and School Practices in the Life of a Latina, his participants revealed their experiences in using their language at home and how it hones their cultural identity.

Similarly, Leveridge (2001) discussed in her report that the language is deeply rooted in the speakers' culture. She stated in her article that the environment or community of the child from the time they were born shaped their life, opinions, and language. The language of a child describes the culture they came from and how they view the world around them. More so, understanding the culture of a particular individual can be done through understanding their language. Further, Alzayed (2015) supported this finding as he mentioned in his journal Preserving Immigrants Native Language and Cultural Identity in Multilingual and Multicultural Societies ways to preserve native languages. One of these is the role of the older to their children, which is to understand that their language lived deep within them. They should provide meaningful experiences to the language and culture and show them that they are essential.

The second essential theme that emerged is the Sense of cultural pride. Based on the participants' responses, Tausug natives are not ashamed of using their language outside their community or with other groups. This finding is supported by the Living In The Philippines (2020) that the Tausug ethnic group values allegiance. They have a lot of ways to show and signify it. In terms of showing loyalty to their tribe, Tausug people live in their culture and tradition and are not ashamed to showcase it even using their language anywhere. Similarly, Talking is Teaching Organization (2020) stated the importance of parents in teaching the children value their language. They emphasized that respecting ones' native language and being proud of it are essential in cultural identity. Thus, parents must show good values and appreciation for the children to imitate and understand the importance of their language and culture thoroughly. In Riehl (2019), she shared her experience meeting a native from Naati, an island in the South Pacific, Vanuatu that supported the finding. Riehl listened to the natives and his pride in using their language. However, Riehl also heard the grief of the natives in losing their mother tongue, just like the other native languages around the world. In his article, he mentioned that out of 7,000 languages spoken today, $50 \%$ to $90 \%$ are at risk of extinction. Nevertheless, the natives make efforts to keep their language alive and maintain a sense of pride in using it.

The third essential theme that emerged is the Conflict of language in conversation. Participants revealed their experiences in communicating with other groups or tribes. Based on the result of data analysis, participants develop a conflict in talking with other groups because of the language barrier. The Tausug opted to use the language of others to communicate to them effectively. Indeed, the ability of an individual to adapt and strategize in language conflict varies from one another. This notion is supported by De Haan and Singer (2010) as they identified the relationship between young children's linguistic ability, home language, and adaptive modifying strategies in peer conflicts. They discussed that children for three years old rely on verbal adaptive modification strategies more than those two years old. They concluded that using psychologically and linguistically complex modification strategies in conflict management, age seems to be a contributor and not entirely the language development.

Parallel to the study of Darquennes (2015), he examined the features of language conflict. His study 
presented areas of focus in scrutinizing language conflict. One of these is the individual language users. Darquennes explained language is a concern with intracultural and intercultural aspects in terms of interpersonal communication. In interpersonal communication, individuals with different languages use the various systems the same with interpersonal language contact, in which individuals use varieties belonging to the same system. Hence, the conflict of language is a broad discussion that can hinder social interaction. Nevertheless, with effort and understanding, tribes may overcome language conflict. On the other hand, in the study of Gao (2002), he discussed the misunderstanding, confusion, and the conflict of language contact. According to him, massive migration and social development is the rise of bilinguals and cross-cultural contact. Different languages and cultures of individuals may bring misunderstanding, confusion, and conflict. Nevertheless, understanding of different cultures and languages of a bilingual may create a meaningful and harmonious relationship with other cultures.

Lastly, the fourth essential theme that emerged is the Importance of research for preservation. Based on the data analysis, participants revealed the importance of research in preserving language and cultural identity. This finding is supported by Klessa (2021) as she pointed out the importance of language documentation in the preservation of language. She stated that language documentation is gathering, programming, and archiving linguistic data of native languages. He emphasized the importance of language documentation in saving endangered languages. Similarly, in the research of Huss (2016), she discussed the importance of research in the survival of endangered languages. According to her, experts conducted research to decline the extinction of native languages and identify ways to preserve them. Thus, she encouraged the revitalization of language through research collaborations of language experts to survive ethnic languages.

On the other hand, a library may serve as a bank of these researches. Olaifa (2014) agreed that the library serves as one of the tools in preserving and keeping native languages. In his journal Language Preservation and Development: The Role of the Library, he examined the library's role in the preservation and development of the language.

\subsection{Implications in Teaching English}

The result of the analysis of the morphological features of Tausug Inflection may use as a reference in Mother Tongue Based-Multilingual Education (MTB-MLE). Kindergarten to Grade 3 applied Mother tongue instruction as part of the K-12 curriculum of the Philippines that was implemented in 2012. In a project team study presented by the Assessment Curriculum \& Technology Research Centre (2020) about Mother Tongue Based-Multilingual Education in the Philippines, they have observed that local languages have been the partner of teachers in instructions. With this, places in the Philippines where Tausug primarily live, like in the Sulu Archipelago or even here in Davao Region, may use this study in understanding the Tausug language and use it effectively in instructions. Hence, in Barangay Hijo, Maco, Davao de Oro, where I conducted the study, this research may benefit the students of Hijo Elementary School, where mostly Tausug natives in the area attend their primary education. The findings of this study may be used by the teachers in creating instructional materials or modules for the Tausug natives in this school as part of the Mother Tongue Instructions.

Moreover, understanding the local languages like the Tausug language can be a tool in introducing the second language to the students. Tomblin (2019) explored the importance of the mother tongue in developing critical and literary skills of the students that are essential in learning a second language. Some theorists and researchers explored and scrutinized the importance of mother tongue in second language acquisition. Thus, this study could help English teachers in understanding the language of Tausug in effectively introduce to the students the English language. The result of this study may also help teachers in contextualization. Contextualizing language in Teaching English allows the students to understand and give meaning to the language. Treating the language in a natural and meaningful context will help the learners acquire comprehension and retention (British Council, 2021). Hence, English teachers could use this research in understanding the Tausug language and its culture and tradition. With this, creating contextualize instructions

90 Consortia Academia Publishing (A partner of Network of Professional Researchers and Educators) 
will be accessible and meaningful.

\section{Concluding Remarks}

Use our language fluently! Speak it correctly! I can still hear my father's voice in those lines. As a native of Tausug living with other groups and tribes, I can only use our language inside our home or when talking to my fellow Tausug. With this, I tend to misuse and mispronounce our language in speaking. My father will always teach and remind us of the proper and correct usage of Tausug and motivates us to use it fluently. Indeed, I am fortunate that I have someone who can guide me in using our language. But how about those Tausug natives who opted not to use their language anymore and did not make efforts in using it fluently?

With that in mind, I have decided to conduct this research, hoping it would impact on my fellow Tausug to use and preserve our language. As I am conceptualizing this study, I found out that there are only a few types of research about the Tausug language. It gives me more reason to do this endeavor. Honestly, until now, I am still in awe of reaching this far in my study. My confidence in starting this research is not high enough for me to finish this. Nevertheless, my intention and efforts in propagating our language and finishing my master's degree pave the way for me to go this far. Hence, this research study showed the complexity and uniqueness of the Tausug language as its culture and tradition. With the Tausug Inflection analyzed, a particular Tausug word may get vast meanings depending on what Tausug Inflection you will use. Today, natives continue to use and propagate these inflections. Also, this research study revealed the efforts of Tausug natives to keep and exercise their traditions and maintain cultural identity amid modern times.

Nonetheless, as professional aiming for a higher degree, the need to conduct this research is like hitting one stone to two birds for me. I could do the final requirement of my course and realize my goal in creating a study that would benefit our tribe and uplift them in using and preserving our language. Actualizing this endeavor was not an easy task but thinking about its result is an achievement for me as a researcher and native of Tausug. Hopefully, this research would serve its purpose and would encourage my fellow Tausug to showcase our own. Mashallah!

\section{References}

Aajami, R. (2019). A cognitive semantic analysis of meaning interrelationship. ResearchGate Publication. https://www.researchgate.net/publication/331789397_A_Cognitive_Semantic_Analysis_of_Meaning_I nterrelationship

African Research Review (2011). A semantic analysis of the language of advertising. https://www.ajol.info/index.php/afrrev/article/view/69286

Akbulut, D. (2017). Effects of morphological awareness on second language vocabulary. Journal of Language and Linguistic Studies. https://files.eric.ed.gov/fulltext/EJ1140424.pdf

Al-khresheh M. (2015). A review study of interlanguage theory. ResearchGate Publication.https://www.researchgate.net/publication/269799663_A_Review_Study_of_Interlanguage_ Theory

Alzayed, N.N.Y. (2015). Preserving immigrants' native language and cultural identity in multilingual and multicultural societies. International Journal of Humanities and Social Science. http://www.ijhssnet.com/journals/Vol_5_No_2_February_2015/30.pdf

Amin, A., \& Shahid, M.I (2013). Influence of language on knowledge sharing a case study of Pakistani workers in selected Swedish multinational companies. https://www.diva-portal.org/smash/get/diva2:630097/FULLTEXT01.pdf

Amos, J. (2012). Digital tools 'to save languages'. https://www.bbc.com/news/science-environment-17081573

Anderson, S. (2020). Morphology. Encyclopedia of Cognitive Science. https://cowgill.ling.yale.edu/sra/morphology_ecs.htm

Assessment Curriculum \& Technology Research Centre (2020). Understanding best practices in mother tongue 
based-multilingual education in the Philippines.

https://actrc.org/projects/understanding-best-practices-in-mtb-mle-in-the

philippines/\#: :text=Mother\%20Tongue\%20Based\%2DMultilingual\%20Education\%20(MTB\%2DML

E) $\% 20$ policy,of\%20instruction\%20after\%20grade $\% 20$ three

Athoilla, M. (2013). Chapter III research method. http://digilib.uinsby.ac.id/13764/6/Bab\%203.pdf

Barton, E. (2002). Resources for discourse analysis in composition studies. https://www.jstor.org/stable/10.5325/style.36.4.575

Bhatia, M. (2018). 3 qualitative research methods you should know. https://humansofdata.atlan.com/2018/03/3-qualitative-research-methods/

Bhuyan, R. (2016). How to code verbatim of the participants in a qualitative research without revealing their identity?.https://www.researchgate.net/post/How_to_code_verbatim_of_the_participants_in_a_qualitati ve_research_without_revealing_their_identity

Blanding, M. (2012). Collaborating across cultures. https://hbswk.hbs.edu/item/collaborating-across-cultures

Bosch, S., Veríssimo, J., \& Clahsen, H. (2019). Inflectional morphology in bilingual language processing: an age-of-acquisition study. https://www.tandfonline.com/doi/full/10.1080/10489223.2019.1570204

Boyce, C., \& Neale, P. (2006). Conducting in-depth interviews: a guide for designing and conducting in-depth interviews for evaluation input. http://www2.pathfinder.org/site/DocServer/m_e_tool_series_indepth_interviews.pdf

Brandes, D., \& McMaster, K. (2017). A Review of morphological analysis strategies on vocabulary outcomes. https://files.eric.ed.gov/fulltext/EJ1165732.pdf

British Council (2021). Contextualisation. https://www.teachingenglish.org.uk/article/contextualisation\#: :text=Contextualisation\%20is\%20puttin $\mathrm{g} \% 20$ language $\% 20$ items,for $\% 20$ language $\% 20$ manipulation $\% 20$ practice $\% 20$ only.\&text=Teaching $\% 20 \mathrm{t}$ he\%20language \%20used\%20to,gives\%20the $\% 20$ target $\% 20$ language\%20context

Calderon, D. (2020). Tausug culture: beliefs, practices, religion, culture, art. https://www.scribd.com/doc/128394815/Tausug-Culture-Beliefs-Practices-Relgion-Culture-Art

Castillo, C. (2019). Language preservation: how countries preserve their language(s). https://ccalanguagesolutions.com/language-preservation-how-countries-preserve-their-languages/

Caulfield, J. (2020). How to do thematic analysis. https://www.scribbr.com/methodology/thematicanalysis/\#: :text=Thematic\%20analysis\%20is\%20a\%20 method,meaning\%20that\%20come\%20up\%20repeatedly

Children's Speech \& Language Services (2020). Morphology and syntax. https://cslstherapy.com/morphology-and-syntax/

Children's Speech and Language Services (2020). Semantic language. https://cslstherapy.com/semantic-language/

Clark, E. (2007). Morphology in language acquisition. Stanford University. https://www.researchgate.net/publication/324505071_Morphology_in_Language_Acquisition

Cohen, J. (2020). Privacy and confidentiality cire current issues in research ethics. Columbia University. https://ccnmtl.columbia.edu/projects/cire/pac/foundation/\#: :text=Privacy\%20relates\%20to\%20the\%20 research,of\%20protecting\%20an\%20individual's\%20privacy

Cresswell J. (2012). Planning, Conducting, and Evaluating Quantitative and Qualitative Research fourth edition. University of Nebraska-Lincoln.

Creswell, J. (2013). Philosophical, paradigm, and interpretive frameworks. https://mycourses.aalto.fi/pluginfile.php/1121681/mod_resource/content $/ 2 / 02 \% 20 J o h n \% 20 \mathrm{~W} \% 20 \mathrm{Cres}$ well\%20Ch.2.pdf

Countries and their Cultures (2020). Tausug - religion and expressive culture. https://www.everyculture.com/East-Southeast-Asia/Tausug-Religion-and-Expressive-Culture.html

Datulio J. (2019). Yang binarawan: a morpho-semantic analysis on Mansaka affixes. Master of Arts in Education Major in English. The Thesis Committee, Graduate School. University of Mindanao, Tagum College Daniel, N. (2009). Morpho-semantic processes in the English language used in a massively multiplayer online

92 Consortia Academia Publishing (A partner of Network of Professional Researchers and Educators) 
role-playing game: a case study of neologisms in Warhammer online. https://www.diva-portal.org/smash/record.jsf?pid=diva2\%3A202572\&dswid=3038

De Haan, D., \& Singer, E. (2012). The relationship between young children's linguistic ability, home language, and their adaptive modifying strategies in peer conflicts. ResearchGate Publication. https://www.researchgate.net/publication/254092423_The_relationship_between_young_children's_ling uistic_ability_home_language_and_their_adaptive_modifying_strategies_in_peer_conflicts

De Jong, R. (2010). The last tribes of Mindanao, the Tausug, people of the current. Destinations: Philippines / Mindanao. http://thingsasian.com/story/last-tribes-mindanao-tausug-people current\#: :text=Tausug\%20or\%20Suluk\%20is\%20the,man\%20and\%20sug\%20meaning\%20current.\&t ext=This $\% 20$ homogeneous $\% 20$ tribe $\% 20$ is $\% 20$ a,mainly $\% 20$ in $\% 20$ coastal $\% 20$ area $\% 20$ communities

Deléger, L., Namer, F., \& Zweigenbaume, P. (2009). Morphosemantic parsing of medical compound words: transferring a French analyzer to English. http://fiamm.free.fr/Publications/IJMI2009_DelegerNamerZweigenbaum.pdf

Domínguez, J. (2016). A morphosemantic investigation of term formation processes in English and Spanish. ResearchGate Publication. https://www.researchgate.net/publication/297591751_A_morphosemantic_investigation_of_term_form ation_processes_in_English_and_Spanish

Dorais, L.J. (2016). Morphosemantics and their limits: three Inuit examples. Université Laval, Québec. https://www.vjf.cnrs.fr/sedyl/amerindia/articles/pdf/A_38_03.pdf

Dudovskiy, J. (2020). Observation. Business Research Methodology. https://research-methodology.net/research-methods/qualitative-research/observation/

Durham University (2020). Research Involving a 'Gatekeeper'. https://www.dur.ac.uk/research.innovation/governance/ethics/considerations/people/gatekeeper/\#: :text $=\mathrm{A} \% 20$ gatekeeper\%20is\%20any\%20person, access\%20to\%20potential\%20research\%20participants

Draquennes, J. (2015). Language conflict research: A state of the art. University ofNamur.https://www.researchgate.net/publication/282317719_Language_conflict_research_A_state_of _the_art

Easwaramoorthy, M., \& Zarinpoush, F. (2006). Interviewing for research. Imagine Canada.http://sectorsource.ca/sites/default/files/resources/files/tipsheet6_interviewing_for_research_en -o.pdf

Economic and Social Research Council (2020). Why consider who will benefit from my research?. https://esrc.ukri.org/funding/guidance-for-applicants/research-ethics/frequently-raised-questions/why-co nsider-who-will-benefit-from-my-research/\#: :text=Benefit $\% 20$ can\%20be\%20defined\%20as,our\%20ec onomy $\% 2 \mathrm{C} \% 20$ individuals $\% 20$ and $\% 20$ society.

Encyclopedia Britannica (2021). Language and culture. https://www.britannica.com/topic/language/Language-typology

Expert System team (2020). Natural language process semantic analysis: definition. https://expertsystem.com/natural-language-process-semantic-analysis definition

Eysenbach, G., \& Tili, J. (2001). Ethical issues in qualitative research on internet communities. https://www.ncbi.nlm.nih.gov/pmc/articles/PMC59687/

Frey, S. (2016). Preserving native American languages by teaching the youngest students. https://edsource.org/2016/preserving-native-american-languages-by-teaching-the-youngest-students/565 007

Galla, C. (2009). Indigenous language revitalization and technology from traditional to contemporary domains. ResearchGate Publication. https://www.researchgate.net/publication/251329976_Indigenous_Language_Revitalizaion_and_Techno logy_From_Traditional_to_Contemporary_Domains

Gao, H. (2002). Language contact - misunderstanding, confusion, and conflicts. Intercultural Communication Studies. Lund University. https://web.uri.edu/iaics/files/09-Hong-Gao.pdf

Gerba, T. (2014). Morphosemantic analysis of Oromo personal names. 
http://citeseerx.ist.psu.edu/viewdoc/download?doi=10.1.1.947.1120\&rep=rep1\&type=pdf

Goswami, T. (2019). The importance of preserving native languages. https://byjus.com/the-learning-tree/importance-preserving-native-languages/

HERD Publication (2016). Focus group discussion. https://www.herd.org.np/uploads/frontend/Publications/PublicationsAttachments1/1485497050-Focus\% 20Group\%20Discussion_0.pdf

Huss, L. (2016). Language learning \& technology. https://link.springer.com/referenceworkentry/10.1007\%2F978-3-319-02329-8_7-1

Hussein, B. (2012). The Sapir-Whorf Hypothesis Today. Department of English Language and Literature, Al-Zaytoonah Private University of Jordan, Amman, Jordan. http://www.academypublication.com/issues/past/tpls/vol02/03/30.pdf

Intercultural Developmental Research Association (2000). Why is it important to maintain the native language? https://www.idra.org/resource-center/why-is-it-important-to-maintain-the-native-language/

Klapuri, A. (2007). Semantic analysis of text and speech. Institute of Signal Processing, Tampere University of Technology, Finland. https://www.cs.tut.fi/sgn/arg/klap/introduction-semantics.pdf

Kithulagoda, H. (2019). Semantic analysis in natural language processing. https://medium.com/voice-tech-podcast/semantic-analysis-in-natural-language-processing-eb9f76b7d20 3

Klessa, K. (2021). Language documentation. http://languagesindanger.eu/book-of-knowledge/language-documentation/

Ladusaw, W. (2020). Meaning (semantics and pragmatics). https://www.linguisticsociety.org/resource/meaning-semantics-and-pragmatics

Lavrakas, P. (2008). Voluntary participation. SAGE Research Methods. https://methods.sagepub.com/reference/encyclopedia-of-survey-research methods/n629.xml\#: : text=Voluntary\%20participation\%20refers\%20to\%20a,scientific\%20communitie s\%20protect\%20this\%20right.

Lester, S. (1999). An introduction to phenomenological research. https://www.rgs.org/CMSPages/GetFile.aspx?nodeguid=7ad9b8d4-6a93-4269-94d2-585983364b51\&la $\mathrm{ng}=\mathrm{en}-\mathrm{GB}$

Leveridge, A. (2001). The relationship between language \& culture and the implications for language teaching. https://www.tefl.net/elt/articles/teacher-technique/language-culture/

Literature Review (2020). Morphological analysis. https://sg.inflibnet.ac.in/bitstream/10603/210232/2/11_morphiological\%20analyser\%202.pdf

Living In the Philippines (2020). Tausug culture, customs, and traditions. https://www.livinginthephilippines.com/culture-and-people/philippine culture/culture-and-traditions/1289-tausugs-culture-customs-and-traditions

Maduay, J. (2017). Kalainan itanding: a linguistic comparative of the morphological features of Mandaya and Kalagan languages. Master of Arts in Education Major in English. The Thesis Committee, Graduate School. University of Mindanao, Tagum College

Matthewson, L. (2017). Semantics in indigenous American languages. University of British Columbia. http://linguistics.sites.olt.ubc.ca/files/2016/09/MatthewsonIJALis100proof.pdf

Mercuri, S.P. (2012). Understanding the interconnectedness between language choices, cultural identity construction and school practices in the life of a Latina educator. https://files.eric.ed.gov/fulltext/EJ1062590.pdf

Moran, M. (2013). Qualitative sample size. https://www.statisticssolutions.com/wp-content/uploads/kalins pdf/singles/qualitative-sample-size.pdf

National Academy of Sciences (2009). On being a scientist: a guide to responsible conduct in research: third edition. https://www.ncbi.nlm.nih.gov/books/NBK214564/\#: :text=Falsification\%20is\%20\%E2\%80\%9Cmanip 
Hatihun nato: A morphosemantic analysis of Tausug inflection

ulating\%20research\%20materials, words\%20without\%20giving\%20appropriate\%20credit.\%E2\%80\%9 $\mathrm{D}$

Newnum, G. (2018). Why language preservation matters (according to experts). http://blog.cyracom.com/why-language-preservation-matters-according-to-experts

Nordquist, R. (May 2020). An introduction to semantics. https://www.thoughtco.com/semantics-linguistics-1692080

Presse, A., \& Lavalee, G. (2012). A long fight begins to save Philippine languages. Rappler News. https://rappler.com/nation/a-long-fight-begins-to-save-philippine-languages

Oficiar, J.E. (2019). Language of homosexuality: a morpho-semantic analysis. European-American Journals. https://www.eajournals.org/journals/international-journal-of-english-language-and-linguistics-research-i jellr/vol-7-issue-5-october-2019/language-of-homosexuality-a-morpho-semantic-analysis/

Ofoegbu, C., \& Usar, I. (2018). A morpho-semantic analysis of lexical creativity of political speech of Nigeria's independence anniversary 2015. Journal of Linguistics, Language, and Igbo studies (JoLLIS). https://www.nigerianjournalsonline.com/index.php/jollis/article/view/94

Omoregbe M. \& Aigbedo, W. (2015). A morpho-semantic analysis of verbs as lexical. https://www.academia.edu/19558804/A_MorphoSemantic_Analysisof_Verbs_as_Lexical_Categories_ Mercy_\%E1\%BB\%8Cmo_re_gbe_and_William_Ighasere_Aigbedo_Categories

Oregon State University (2020). Research involving deception. https://research.oregonstate.edu/irb/policies-and guidance/guidance/researchinvolvingdeception\#: :text=Overview,manipulation $\% 20 \mathrm{of} \% 20 \mathrm{one}$ 's 20 self $\% 2$ Dconcept

O'Grady, W. (2006). The problem of verbal inflection in second language acquisition. http://www.ling.hawaii.edu/faculty/ogrady/Verbal_inflection_in_SLA.pdf

Öz, H. (2014). Morphology and implications for English language teaching. ResearchGate Publication. https://www.researchgate.net/publication/266731962_Morphology_and_Implications_for_English_Lan guage Teaching

Pathak, V., Jena, B., \& Kalra, S. (2013). Qualitative research. https://www.ncbi.nlm.nih.gov/pmc/articles/PMC3757586/

Rastle, K. (2018). The place of morphology in learning to read in English. https://www.sciencedirect.com/science/article/pii/S0010945218300571

Riehl, A. (2019). Why are languages worth preserving? https://www.sapiens.org/language/endangered-languages/

Rogers, N. (2020). Saving a language, preserving a culture: new translations of Jicarilla Apache texts. http://news.unm.edu/news/saving-a-language-preserving-a-culture

Rovira, L. (2008). The relationship between language and identity: the use of the home language as a human right of the immigrant. https://www.redalyc.org/pdf/4070/407042009004.pdf

Salkind, N. (2010). Triangulation. Sage Publication. https://methods.sagepub.com/reference/encyc-of-research-design/n469.xml

Sage Publication (2004). Ethical considerations. https://www.sagepub.com/sites/default/files/upmbinaries/4999_Polonski_Chapter_5.pdf

Sage Publication (2020). Participants in a focus group. https://www.sagepub.com/sites/default/files/upm-binaries/24056_Chapter4.pdf

Scott, M. (2009). Semantic analysis. https://www.sciencedirect.com/topics/computer-science/semantic-analysis

Shahnazarian, D., Hagemann, J., Aburto, M., \& Rose, S. (2009). Informed consent in human subjects' research. University of Southern California. https://oprs.usc.edu/files/2017/04/Informed-Consent-Booklet-4.4.13.pdf

Shashkevich A. (2019). The power of language: how words shape people, culture. https://news.stanford.edu/2019/08/22/the-power-of-language-how-words-shape-people-culture/

Sim, J., \& Waterfield J. (2019). Focus group methodology: some ethical challenges. https://link.springer.com/article/10.1007/s11135-019-00914-5\#: :text=Focus\%20group\%20methodolog y\%20generates\%20distinct,anonymity\%3B\%20and\%20risk\%20of\%20harm 
Camlian, F., \& De Leon, M. G.

Soto, L. (2021). Preserving language \& culture. https://www.scholastic.com/teachers/articles/teaching-content/preserving-language-culture/

Stowe, M. (2020). Teaching morphology: enhancing vocabulary development and reading comprehension. https://education.wm.edu/centers/ttac/resources/articles/teachtechnique/teachingmorphology/index.php

Talking is Teaching Organization (2020). Tips for using language at home and in the community. https://www2.ed.gov/documents/early-learning/talk-read-sing/language-en.pdf

Tan, E. (1967) The phonology of Tausug. https://open.library.ubc.ca/cIRcle/collections/ubctheses/831/items/1.0105420

Tausug Familiarization Course (2020). http://jblmflc.com/Tausug/PDF/Introduction.pdf

The Editors of Encyclopedia Britannica (2021). Tausug people. https://www.britannica.com/topic/Tausug

The Editors of Encyclopedia Britannica (2021). Inflection. https://www.britannica.com/topic/inflection

The Pennsylvania State University (2020). Falsification, fabrication, plagiarism. https://www.e-education.psu.edu/bioet533/node/654

The Regents of the University of California (2013). Conflict of interest in research. https://coi.ucsf.edu/\#: :text=The\%20term\%20\%E2\%80\%9Cconflict\%20of\%20interest,in\%20conductin g\%20or\%20reporting\%20research

The University of Auckland (2019). Thematic analysis I a reflexive approach. https://www.psych.auckland.ac.nz/en/about/thematic-analysis.html

Tomblin, B. (2019). The importance of mother tongue in education. https://ie-today.co.uk/people-policy-politics/the-importance-of-mother-tongue-in-education/

Tutorial Point (2020). Natural language processing - semantic analysis. https://www.tutorialspoint.com/natural_language_processing/natural_language_processing_semantic_a nalysis.htm

United Language Group (2021). The preservation of culture one language at a time. https://www.unitedlanguagegroup.com/blog/the-preservation-of-culture-one-language-at-a-time

University of Oregon (2020). Examples of potential risks to subjects.

https://research.uoregon.edu/manage/research-integrity-compliance/human-subjects-research/examplespotential-risks-subjects

University of Oxford (2020). Plagiarism.

https://www.ox.ac.uk/students/academic/guidance/skills/plagiarism\#: :text=Plagiarism\%20is\%20prese nting\%20someone\%20else's,is\%20covered\%20under\%20this\%20definition.

University of Southern California (2020). Office for the protection of research subjects.

https://oprs.usc.edu/irb-review/recruitment-of-research

participants/\#: :text=Recruitment $\% 20$ involves\%20attracting\%20and\%20selecting,soliciting\%20volunt eers\%20in\%20public\%20spaces.

Viramdami, I., \& Himmawati, D. (2017). Morpho-semantic analysis in electronic product Brands. State University of Surabaya. https://core.ac.uk/download/pdf/230652201.pdf

Villa, D. (2002). Integrating technology into minority language preservation and teaching efforts: an inside job. https://scholarspace.manoa.hawaii.edu/bitstream/10125/25163/1/06_02_villa.pdf

Wahlström, M. (2017). Loss of case inflection in Bulgarian and Macedonian. https://researchportal.helsinki.fi/en/publications/loss-of-case-inflection-in-bulgarian-and-acedonian

Wakweya, G. (2017). Inflectional morphology in Mecha Oromo. https://academicjournals.org/journal/JLC/article-abstract/47DCAA765496

Willig, C. (2017). Interpretation in qualitative research. Sage Publication. https://in.sagepub.com/sites/default/files/upmassets/82114_book_item_82114.pdf

Williams, C. (2007) Research methods. Grand Canyon University Journal of Business \& Economic Research. Volume 5, Number 3

Wolter, J., D'zatko, K., \& Wood, A. (2009). The influence of morphological awareness on the literacy development of first-grade children. ResearchGate Publication. https://www.researchgate.net/publication/26328465_The_Influence_of_Morphological_Awareness_on_

96 Consortia Academia Publishing (A partner of Network of Professional Researchers and Educators) 
Hatihun nato: A morphosemantic analysis of Tausug inflection

the_Literacy_Development_of_First-Grade_Children/link/0f31753a1b71f766d3000000/download Yliopisto, J. (2010). Phenomenological research.

https://koppa.jyu.fi/avoimet/hum/menetelmapolkuja/en/methodmap/strategies/phenomenological-resear $\mathrm{ch}$ 
Camlian, F., \& De Leon, M. G.

98 Consortia Academia Publishing (A partner of Network of Professional Researchers and Educators) 